\title{
Pore Size Changes in Marine Soft Soil under Various Freezing Conditions
}

\author{
Bowen Kong ${ }^{1,2} \mathbb{D}$, Fan Xia ${ }^{1}$, Bingqi Yu ${ }^{1}$, Tangdai Xia ${ }^{1}$ and Zhi Ding ${ }^{2,3, *}$ \\ 1 Research Center of Coastal and Urban Geotechnical Engineering, College of Architecture and Civil \\ Engineering, Zhejiang University, Hangzhou 310015, China; kbw@zju.edu.cn (B.K.); \\ 21812002@zju.edu.cn (F.X.); 11712028@zju.edu.cn (B.Y.); xtd@zju.edu.cn (T.X.) \\ 2 Faculty of Science and Technology, University of Macau, Macau 999078, China \\ 3 Department of Civil Engineering, Zhejiang University City College, Hangzhou 310015, China \\ * Correspondence: dingz@zucc.edu.cn; Tel.: +86-0571-8801-8968
}

Received: 12 February 2020; Accepted: 25 February 2020; Published: 4 March 2020

\begin{abstract}
Artificial freezing methods can help highlight the mechanical properties of marine clay. The construction of cross passages in metro tunnels employs the freezing method. Freeze-thaw circulation, which is part of the process, affects the engineering properties of clay and produces differential settling. This paper describes the percentages of specific diameters of frozen-thawed soil under different freezing temperatures, measured with the help of nuclear magnetic resonance (NMR). In response to the experimental results, a weakening effect of freezing temperature and speed on soft soil is proposed. All sizes of undisturbed soil pores tend to increase under various freezing temperatures. Owing to differences in free water content, the water in medium pores freezes quicker than that in tiny pores. The quicker the freezing, the greater the resulting void ratio. Finally, potential reasons for changes in pore size under different freezing conditions are explained from a microcosmic perspective.
\end{abstract}

Keywords: marine soil; NMR; soil pores; frozen-thawed soil; freezing temperature; AGF; freezing speed

\section{Introduction}

Artificial ground freezing (AGF) [1] was employed to stabilize and waterproof passageways constructed under seawater and offshore engineering. For marine soft soil, AGF is economical, convenient, eco-friendly, and time-consuming. However, because the freeze-thaw cycle destroys the internal structure of the soil skeleton, weakening its structure and reducing its dynamic characteristics [2], tunnels using AGF settle much more than others do [3]. The freezing-thawing action is thus a crucial part of evaluating structural damage to tunnels [3].

Many factors influence the freezing effect. Scientists have conducted extensive research to isolate soil damage mechanisms under freezing conditions. A constitutive model [4] featuring ice pressure, liquid water pressure, and total stress as state variables was devised to study the thermo-hydro-mechanical process of soil induced by artificial freezing. The thermal conductivity of silty soil increases with the initial level of water content during the freezing-thawing process [5]. Adsorbed cations also affect unfrozen water in clay [6], so that soils containing smectite have the largest unfrozen water content when treated with $\mathrm{Na}+$ cations, and a marked reduction with $\mathrm{K}+$ treatment. Reference [7] discusses the influence of pressure melting and ice-water phase transition on the mechanical behavior of frozen soil. Except for relative density and confining pressure [8], the seepage-flow condition is also a key factor influencing the freezing effect of freezing action [9].

Several models have been proposed with which to predict changes in soil after freezing. A linearized theory of one-dimensional thermoplastic consolidation is given for a layer of soft soil in [10]. 
Based on the phase transition theory, a hysteresis is proposed [11] for estimating the freezing-thawing effect. Reference [12] proposes a fully instrumented physical model (hermo-hydro-mechanical numerical) of the evolution of the soil properties during freezing and thawing. Reference [13] give a practical model of deformation prediction in soft clay after artificial ground freezing. Reference [14] proposes a theoretical extension of the permafrost evolution in porous media based on the extension of normal freezing curve theory.

Although macrotheoretical foundations abound, the essence of property change in soil is microstructure change [15]. Research has examined unfrozen water content in frozen soil [16]. Reference [17], for example, gives a soil freezing characteristic curve for unfrozen water, and a method for calculating the unfrozen water content of silty clay is given in [18]. However, subway loads are different from small-strain loads [19], with frozen water having the greatest influence on base deformation. The freezing expansion of water [20] enlarges the pores of soil, creating a deformation space. For saturated soil, the volume of the pores corresponds to the volume of water. Finding a way of accurately measuring changes of frozen water in soil then becomes the most pressing problem.

There are many ways of measuring soil porosity, including the use of an SEM (scanning electron microscope), the mercury intrusion method, and high-speed photography. In a break from traditional methods, low-field NMR technology offers a quick, lossless, and repeatable way of precisely measuring water in samples. Introduced to civil engineering [21] only recently, it uses an NMR signal to calculate soil water content and pore diameters [22]. NMR is a direct and accurate method [23] for studying the microstructure of clay, including variations in pore size and pore size distribution [24]. Although a few NMR-based tests of frozen soft soil have been proposed, changes to percentages of specific diameters in frozen-thawed marine soft soil under various freezing temperatures remain unclear.

In this paper, the authors investigate the deformation mechanism with reference to changes in the percentage of specific diameters during the freezing process. The percentage change of tiny pores $(0-0.2 \mu \mathrm{m})$, medium pores $(0.2-10 \mu \mathrm{m})$, and large pores $(>10 \mu \mathrm{m})$ is used to explore the mechanism of the freezing process and thereby shed light on the roles of temperature and freezing speed. Ultimately, several important conclusions are drawn to supplement the theoretical basis for uneven settling in freeze-thaw construction.

\section{Materials and Methods}

Soil samples were taken from the Hangzhou (Figure 1) Metro Line 2 LZ station, 15 m underground. Two kinds of uniform remolded soils were used to accurately quantify temperature effects (undisturbed soil has properties closest to the artificial frozen soil affected by freezing). In all, three soil samples were used in the experiments: origin-state soil (O-S soil), vacuum preloading remolded soil (V-R soil), and compaction remolded soil (C-R soil). The low-field NMR technique was used to obtain pore diameter data.

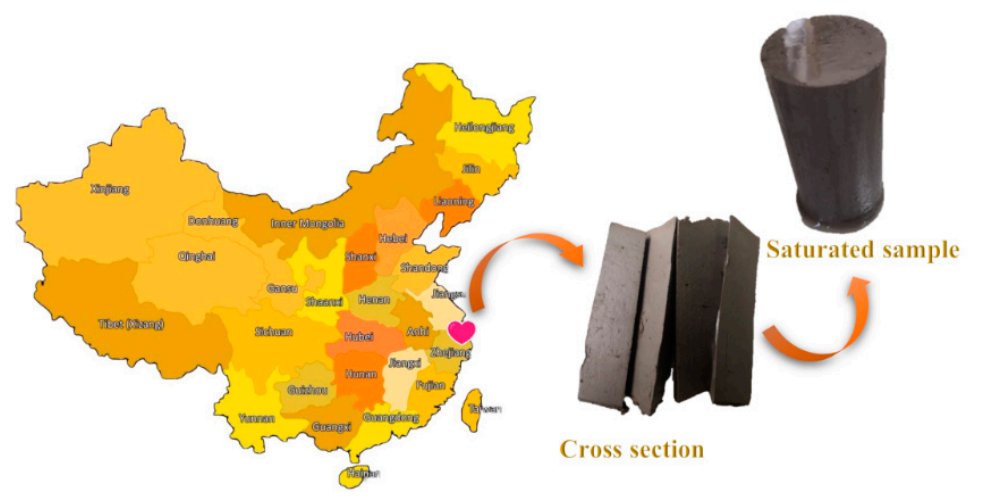

Figure 1. Source of soil samples. 


\subsection{Soil Samples}

The deep thick marine silty soft clay of Hangzhou from late quaternary has poor mechanical properties. The physical and mechanical properties are characterized by low strength, high compressibility, low permeability, and high sensitivity. Illite and illite -montmorillonite minerals are the main clay components. The soil has density $\varrho=1.82 \mathrm{~g} / \mathrm{cm}^{2}$, specific gravity Gs $=2.75$, water content $\omega=45 \%$, plastic limit $\omega p=33.4 \%$, liquid limit $\omega \mathrm{L}=51.6 \%$, plasticity index $\mathrm{Ip}=18.2$. The reference range of the thermal conductivity is $0.8-1 \mathrm{~W} \cdot \mathrm{m}^{-1} \mathrm{~K}^{-1}$ [25]; the grain composition is shown in Figure 2.

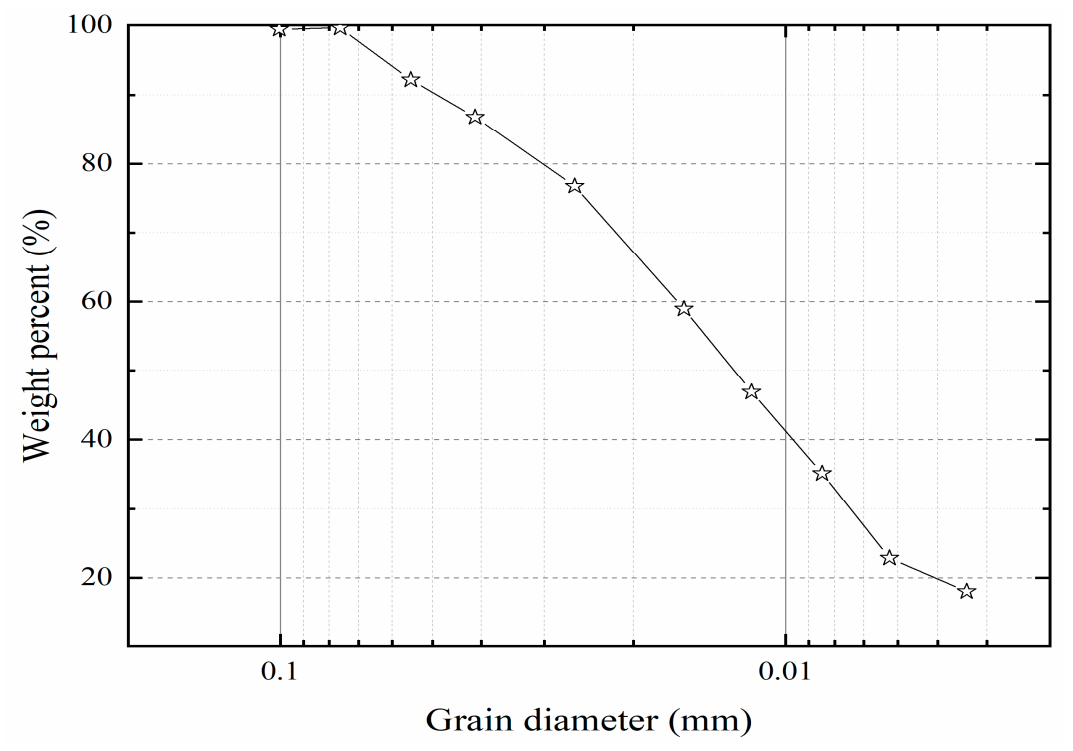

Figure 2. Grain composition.

\subsubsection{Undisturbed Soil Sample}

Undisturbed soil in its original state (O-S soil) was extracted from 15-20 m underground. As the underground water level was $-1 \mathrm{~m}$, the soil sample was saturated. Metal tubular containers were used to collect and store the clay samples. Wax was applied to both ends of a metal tubular container to prevent water loss. The undisturbed soil used comes from organic matter deposition and has undergone natural consolidation for thousands of years.

After freezing, the frozen-thawed soil samples were prepared in a cylinder $50 \mathrm{~mm}$ in diameter and $100 \mathrm{~mm}$ high. Although impurities were removed as much as possible during sample cutting, the soil was, inevitably, not especially uniform. Thus, undisturbed soil can truly reflect pore changes in foundation soil during artificial freezing.

\subsubsection{Vacuum Preloading Remolded Soil Sample}

Vacuum preloading remolded soil (V-R soil) was prepared for accurate simulation of the undisturbed soil, with the undisturbed soil put into a drying oven at $200{ }^{\circ} \mathrm{C}$ for $24 \mathrm{~h}$ and ground into powder, which was then mixed with hot water and put in a vacuum container at $-450 \mathrm{kp}$ for 6 weeks. The uniformity of the remolded soil is demonstrated. The design of the remolded soil was based on multichannel intelligent remolded soil vacuum preloading equipment [26].

The remolded soil was prepared in a cylinder $38 \mathrm{~mm}$ in diameter and $76 \mathrm{~mm}$ high. Next, the cylinder was placed in a vacuum saturation cylinder and vacuumed at $-0.1 \mathrm{MPa}$ for $3 \mathrm{~h}$, then soaked at atmospheric pressure for $12 \mathrm{~h}$ to produce saturated remolded soil.

\subsubsection{Compaction Remolded Soil Sample}

The compaction method is the most common way of making soil samples. With an initial moisture content of $15 \%, 140 \mathrm{~g}$ of the same powder as V-R soil was mixed with $21 \mathrm{~g}$ of air-free water and the 
resulting mixture divided into 5 parts: $31.8 \mathrm{~g}, 32.0 \mathrm{~g}$, $32.2 \mathrm{~g}, 32.4 \mathrm{~g}$, and $32.6 \mathrm{~g}$. The soil was then compacted into a cylinder $38 \mathrm{~mm}$ in diameter and $76 \mathrm{~mm}$ high, with a $15.2 \mathrm{~mm}$ compaction height for each layer, to ensure uniformity. The C-R soil sample was then saturated the same way as V-R soil samples.

\subsection{The Use of NMR Technique}

In the test, the MesoMR23-060H-I low-field NMR equipment depicted in Figure 3, provided by the Newmag Company in Shanghai, was used to study the pores of the saturated soil. The central principle of NMR is that a nucleus always spins around its own axis at a constant frequency, generating a magnetic field when the number of protons is odd and the number of neutrons is even. Because the $\mathrm{H}$ element in water follows this law, it can be used to calculate water content. However, obtaining this number is a problem. In general, each proton spins in a random order, with magnetization vectors canceling each other out. Thus, water does not show a macroscopic magnetization vector. However, on exposing the element to a magnetic field, the protons enter a nuclear magnetic state.

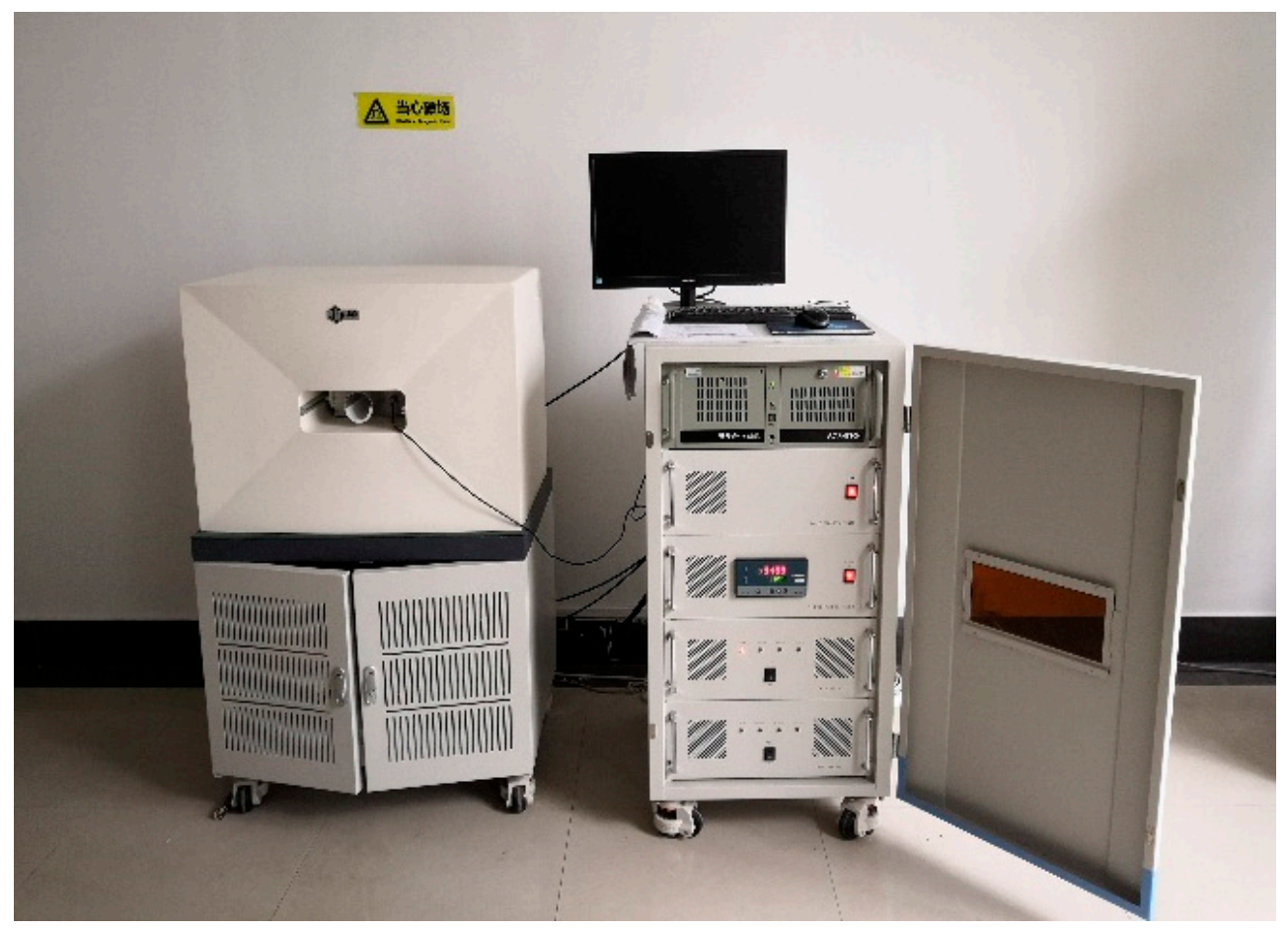

Figure 3. Low-field NMR equipment.

The precession causes the magnetic field of each proton to have a directionally stable longitudinal magnetization vector and a rotating transverse magnetization vector. Because there are slightly more protons in the low-energy state than in the high-energy state, the element produces a macroscopic longitudinal magnetization vector. Magnetic resonance (MR) cannot detect the longitudinal magnetization vector, but the rotating transverse magnetization vector can be observed. After a $90^{\circ}$ pulse, the microscopic transverse magnetization vectors of the protons are summed to produce a macroscopic transverse magnetization vector. Finally, the MR detects the rotating transverse magnetization vector, which cuts the magnetic line of force.

After the RF pulse is stopped, the lateral macroscopic magnetization vector gradually decreases to zero and the longitudinal macroscopic magnetization vector gradually returns to equilibrium from zero. $T_{1}$ is the time when the macroscopic longitudinal magnetization vector recovers to $63 \%$ of its maximum value, and the $T_{2}$ value represents the time required for the transverse magnetization vector to decay to approximately $37 \%$ of its maximum value. 
Assuming that the shape of the pore is ideally the same as it was set, the condition for the fast diffusion regime is satisfied, and that the diffusion time is negligible, the relationship of pore radius $R$ and $T_{2}$ can be given by the following equation:

$$
\frac{1}{T_{2}} \approx \rho_{2}\left(\frac{S}{V}\right)_{\text {pore }}=\rho_{2} \frac{\propto}{R}
$$

In Equation (1), $\rho_{2}$ represents the surface relativity, which is determined by the test material. There is a linear relationship between $T_{2}$ and $R$. The experience value 10 is taken to be the $\rho_{2}$ value. $S$ is the surface area of the pore and V the volume of the pore water. For the shape factor $\propto$, the material's pores are always assumed to be planar, cylindrical, and spherical, with values of 1, 2, and 3 respectively. In this test, the pores of the soil are assumed to be cylindrical, as they were in the shape of fissures.

Soil consists of a variety of particles; therefore, it is more likely to reach full saturation than other materials. The water in soil includes free water and adsorbed water, both of which greatly influence its mechanical properties. Distribution of pore size, a key parameter of soil, can be detected using the NMR technique, after which the measured $T_{2}$ value can be converted into pore distribution by inversion.

The saturated soil samples previously made were divided into two equally large ones to adapt to the $60 * 60$ uniform magnetic field of the NMR equipment. Before the test, five standard samples with known moisture content were checked to see if they met the specified parameters, ensuring a degree of fit exceeding 0.999. The following parameters were used: $\mathrm{SW}=333.333, \mathrm{SF}=21, \mathrm{RFD}=0.010$, $\mathrm{RG} 1=20, \mathrm{P} 1=20, \mathrm{DRG} 1=3, \mathrm{TD}=166692, \mathrm{PRG}=1, \mathrm{TW}=1500, \mathrm{NS}=16, \mathrm{P} 2=40, \mathrm{TE}=0.250, \mathrm{NECH}$ $=2000$. The calibration result was 0.9998 . The NMR test results were influenced by parameter-setting, metal impurities in the soil sample, magnetic uniformity, and calibration accuracy. A limitation of the NMR test was fixed error; to minimize this, the analysis focused on the change in pore size distribution.

The undisturbed soil was slightly uneven, with the uniform remolded soil needing to replace it to obtain minimal changes. To explore which soil sample was suitable for accurate simulation of the undisturbed soil, three soil samples were scanned using an NMR instrument, as indicated in Figure 4.

The three kinds of soil showcased a main peak of tiny pores and a sub-peak of medium pores; thus, the way in which the pores changed after the freezing action was key in choosing the required remolded soil. As Figure 5 shows, pore size changes in the C-R soil were far less than that in the undisturbed and V-R soils. The V-R soil had a percentage change curve similar to that of the undisturbed soil, and the change in the C-R soil was more pronounced, allowing the change rule to be easily seen. The V-R soil was thus chosen to simulate the undisturbed soil.

The original soil sample showed maximum accuracy in simulating different freezing conditions. However, as every other kind of geotechnical test, the NMR also questions if the original soil is too non-uniform and would restrict the obtaining of precise percent change under gentle variation. The remolded soil sample, on the other hand, has almost the same pore size distribution (Figure 6), and is thus more reliable.

The authors used the O-S soil to identify the turning point temperature to be between $-30{ }^{\circ} \mathrm{C} \sim 0^{\circ} \mathrm{C}$, following which the V-R soil, which had the most similar change rule as the original soil, was chosen to accurately quantify temperature effects to further obtain precise turning point and freezing progression. 


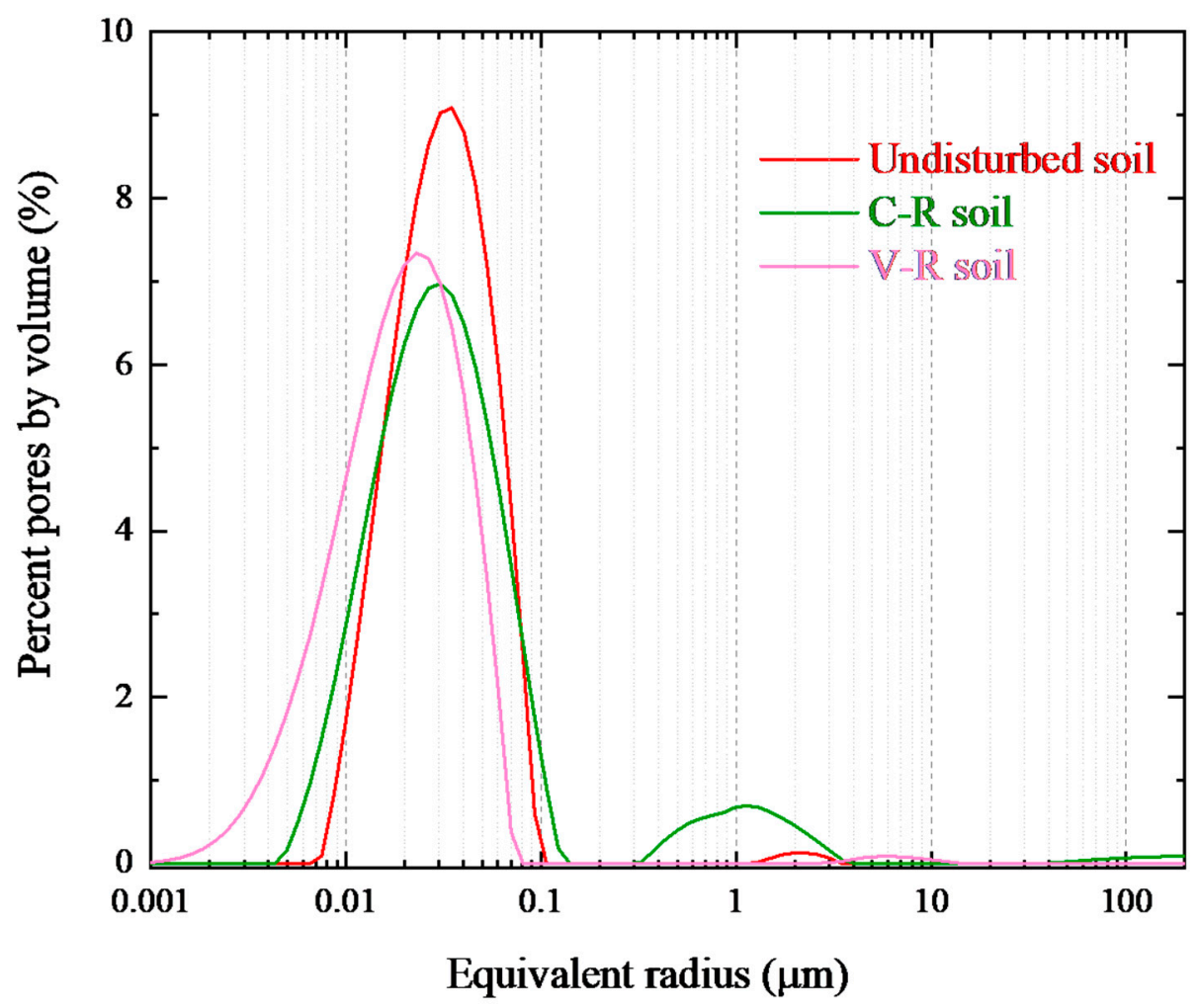

Figure 4. Test results of the three types of soil samples.

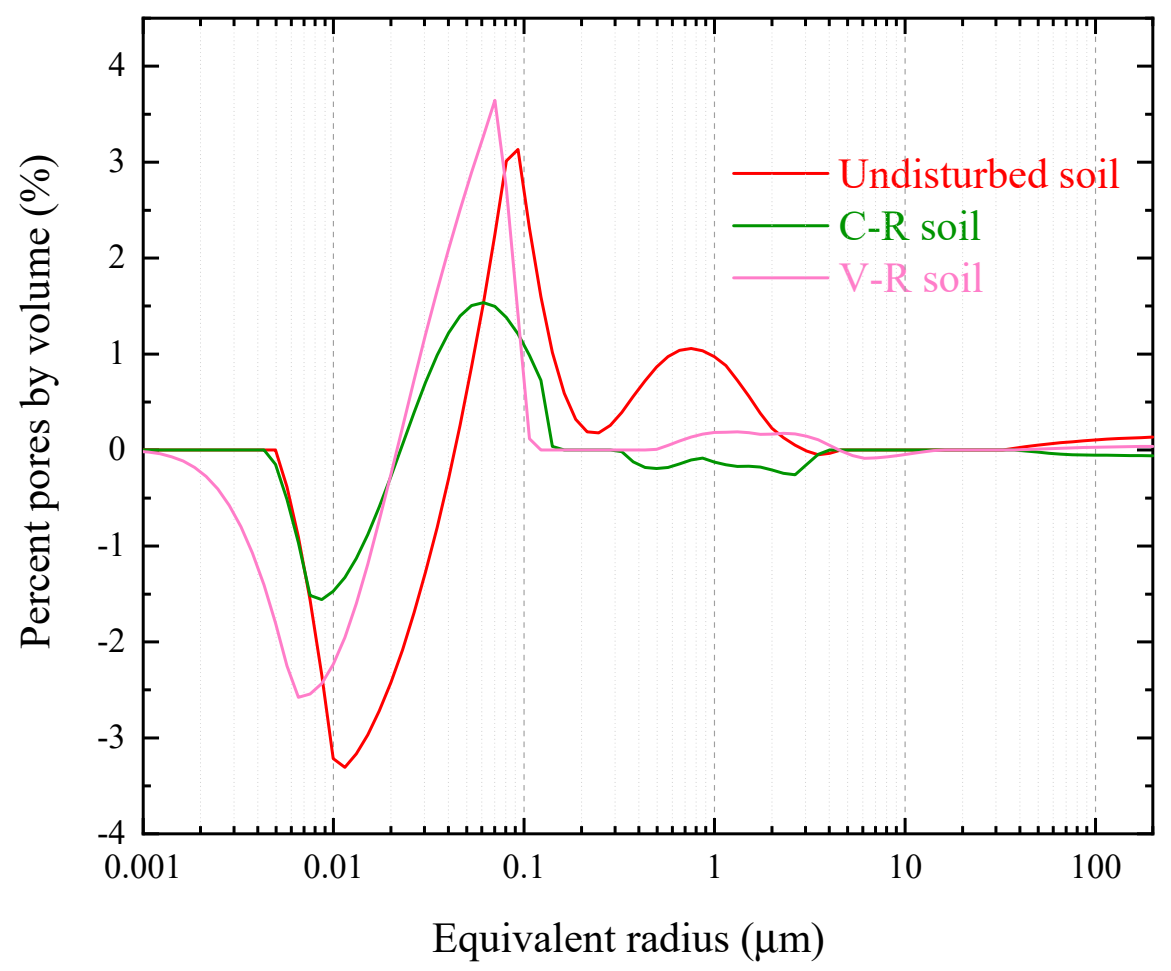

Figure 5. Pore distribution changes in different soil samples. 


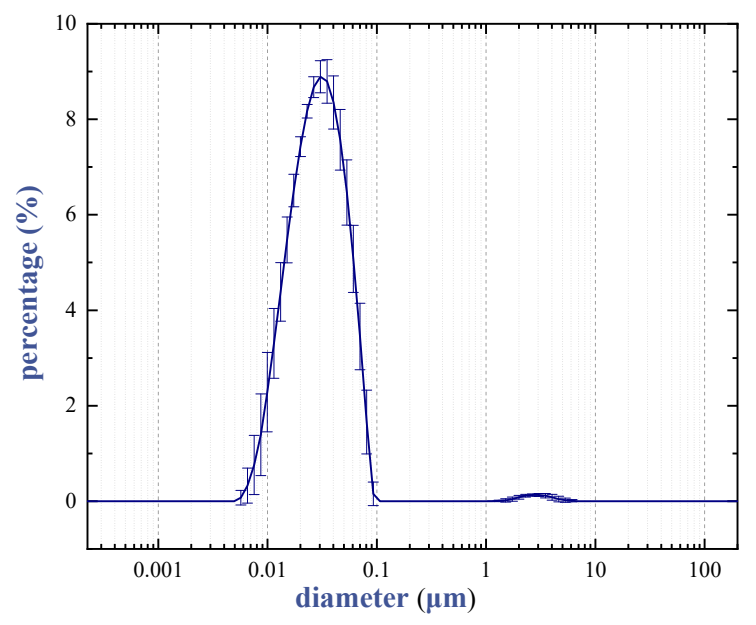

(a)



(b)

Figure 6. Pore distribution error bar for all soil samples. (a) Error bar for O-S soil samples; (b) Error bar for V-R soil samples.

\subsection{Freezing Plan}

Saturators are of two sizes: $50 * 100 \mathrm{~mm}$ and $38 * 76 \mathrm{~mm}$ cylinders. Because the original-state soil sample was not uniform enough, the larger saturators were used to make an O-S sample. The smaller the volume of sample, the more accurate the test results are, because uniform magnetic field volume is limited. Taking everything into consideration, to avoid the effect of size, each group variate shares the same size saturators. NMR test equipment have a maximum uniform magnetic field of $60 * 60 \mathrm{~mm}$, so the prepared soil samples were cut into two equal pieces. Thus, for every serial number in Table 1 , there are two samples for parallel trials. The average of the two experiments is taken into account if the trend is consistent. The test is repeated if the parallel trials show huge differences, to ensure that the final results are reliable.

Table 1. Test plan.

\begin{tabular}{ccccccc}
\hline $\begin{array}{c}\text { Serial } \\
\text { Number }\end{array}$ & $\begin{array}{c}\text { Soil } \\
\text { Types }\end{array}$ & $\begin{array}{c}\text { Freezing } \\
\text { Temperature }\end{array}$ & $\begin{array}{c}\text { Freeze } \\
\text { Time }\end{array}$ & $\begin{array}{c}\text { Thaw } \\
\text { Time }\end{array}$ & $\begin{array}{c}\text { Diameter } \\
\text { Height }\end{array}$ & $\begin{array}{c}\text { Freeze } \\
\text { Speed }\end{array}$ \\
\hline 01 & $\mathrm{O}-\mathrm{S}$ & $-5{ }^{\circ} \mathrm{C}$ & $48 \mathrm{~h}$ & $48 \mathrm{~h}$ & $50 * 50 \mathrm{~mm}$ & fast \\
02 & $\mathrm{O}-\mathrm{S}$ & $-10^{\circ} \mathrm{C}$ & $48 \mathrm{~h}$ & $48 \mathrm{~h}$ & $50 * 50 \mathrm{~mm}$ & fast \\
03 & $\mathrm{O}-\mathrm{S}$ & $-15^{\circ} \mathrm{C}$ & $48 \mathrm{~h}$ & $48 \mathrm{~h}$ & $50 * 50 \mathrm{~mm}$ & fast \\
04 & $\mathrm{O}-\mathrm{S}$ & $-20^{\circ} \mathrm{C}$ & $48 \mathrm{~h}$ & $48 \mathrm{~h}$ & $50 * 50 \mathrm{~mm}$ & fast \\
05 & $\mathrm{O}-\mathrm{S}$ & $-25^{\circ} \mathrm{C}$ & $48 \mathrm{~h}$ & $48 \mathrm{~h}$ & $50 * 50 \mathrm{~mm}$ & fast \\
06 & $\mathrm{O}-\mathrm{S}$ & $-30^{\circ} \mathrm{C}$ & $48 \mathrm{~h}$ & $48 \mathrm{~h}$ & $50 * 50 \mathrm{~mm}$ & fast \\
07 & $\mathrm{C}-\mathrm{R}$ & $-20^{\circ} \mathrm{C}$ & $48 \mathrm{~h}$ & $48 \mathrm{~h}$ & $50 * 50 \mathrm{~mm}$ & fast \\
08 & $\mathrm{~V}-\mathrm{R}$ & $-20^{\circ} \mathrm{C}$ & $48 \mathrm{~h}$ & $48 \mathrm{~h}$ & $50 * 50 \mathrm{~mm}$ & fast \\
09 & $\mathrm{~V}-\mathrm{R}$ & $-1{ }^{\circ} \mathrm{C}$ & $24 \mathrm{~h}$ & $24 \mathrm{~h}$ & $38 * 38 \mathrm{~mm}$ & fast \\
10 & $\mathrm{~V}-\mathrm{R}$ & $-3{ }^{\circ} \mathrm{C}$ & $24 \mathrm{~h}$ & $24 \mathrm{~h}$ & $38 * 38 \mathrm{~mm}$ & fast \\
11 & $\mathrm{~V}-\mathrm{R}$ & $-5{ }^{\circ} \mathrm{C}$ & $24 \mathrm{~h}$ & $24 \mathrm{~h}$ & $38 * 38 \mathrm{~mm}$ & fast \\
12 & $\mathrm{~V}-\mathrm{R}$ & $-8{ }^{\circ} \mathrm{C}$ & $24 \mathrm{~h}$ & $24 \mathrm{~h}$ & $38 * 38 \mathrm{~mm}$ & fast \\
13 & $\mathrm{~V}-\mathrm{R}$ & $-10^{\circ} \mathrm{C}$ & $24 \mathrm{~h}$ & $24 \mathrm{~h}$ & $38 * 38 \mathrm{~mm}$ & fast \\
14 & $\mathrm{~V}-\mathrm{R}$ & $-20^{\circ} \mathrm{C}$ & $24 \mathrm{~h}$ & $24 \mathrm{~h}$ & $38 * 38 \mathrm{~mm}$ & fast \\
15 & $\mathrm{~V}-\mathrm{R}$ & $-20^{\circ} \mathrm{C}$ & $24 \mathrm{~h}$ & $24 \mathrm{~h}$ & $38 * 38 \mathrm{~mm}$ & fast \\
16 & $\mathrm{~V}-\mathrm{R}$ & $-20^{\circ} \mathrm{C}$ & $24 \mathrm{~h}$ & $24 \mathrm{~h}$ & $38 * 38 \mathrm{~mm}$ & medium \\
17 & $\mathrm{~V}-\mathrm{R}$ & $-20^{\circ} \mathrm{C}$ & $24 \mathrm{~h}$ & $24 \mathrm{~h}$ & $38 * 38 \mathrm{~mm}$ & slow \\
\hline
\end{tabular}

The low-temperature test chamber used for freezing the soil had both time and temperature settings, with temperature spanning $-40{ }^{\circ} \mathrm{C}$ to $30^{\circ} \mathrm{C}$ and time $0 \mathrm{~h}$ to $999 \mathrm{~h}$. The average temperature of the frozen wall design was $-20^{\circ} \mathrm{C}$ [27], and that of the cooling medium was about $-30{ }^{\circ} \mathrm{C}$. The freezing 
process was deemed complete when the pipeline reflux reached $-20^{\circ} \mathrm{C}$, a process that took $5-6$ days. As per the freezing temperature and freezing time, the $50^{*} 100$ remolded clay was frozen for $48 \mathrm{~h}$ at $-5^{\circ} \mathrm{C},-10{ }^{\circ} \mathrm{C},-15{ }^{\circ} \mathrm{C},-20^{\circ} \mathrm{C},-25^{\circ} \mathrm{C}$, and $-30{ }^{\circ} \mathrm{C}$.

Furthermore, a turning point was seen in the $0{ }^{\circ} \mathrm{C} 10^{\circ} \mathrm{C}$ range [13]. The remolded soil samples, which were more uniform than the undisturbed soil, were used to find the turning point. As Figure 6 shows, diameter changes in the V-R soil were closer to that of the undisturbed soil than the V-R soil. The $38 * 76$ remolded clay was frozen for $24 \mathrm{~h}$ at $-3{ }^{\circ} \mathrm{C},-5^{\circ} \mathrm{C},-8{ }^{\circ} \mathrm{C}$, and $-10{ }^{\circ} \mathrm{C}$ to obtain its turning point.

As Table 1 shows, for the $50 * 100$ remolded clay, $48 \mathrm{~h}$ freezing time was proportional to the actual engineering process. For the $38 * 76$ remolded soil, $24 \mathrm{~h}$ freezing time was sufficient. In a freeze-thaw cycle, the remolded clay was frozen at the set experimental temperature for a specified amount of time in a low-temperature freezing box, and then thawed in the box with constant temperature and humidity.

\section{Temperature Profile of the Soil Sample}

A low-temperature freezer is a key piece of testing equipment. Freezing quality is affected by compressor power, indoor temperature, soil temperature, radiogenic heat, heat preservation material, and degree of seal. To reduce additional changes in pore size distribution, air conditioning was used to maintain an indoor temperature of $24^{\circ} \mathrm{C}$. A temperature recorder was used to record the temperature of the soil center every $15 \mathrm{~min}$. If the undisturbed soil was observed to be frozen, another matching sample was checked to see if it displayed the same property at the same time. Unlike other research works where a part of the probe is normally out of the soil sample, as seen in Figure 7a [28], in thus study, the whole probe was completely inserted into the center of the soil sample to ensure that it was unaffected by the outside temperature. The center of the soil sample get cross-sectional temperature from that part of the soil that is not in contact with the freezing media.

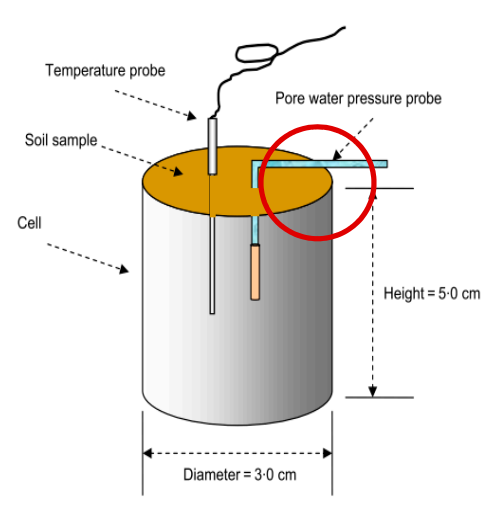

(a)

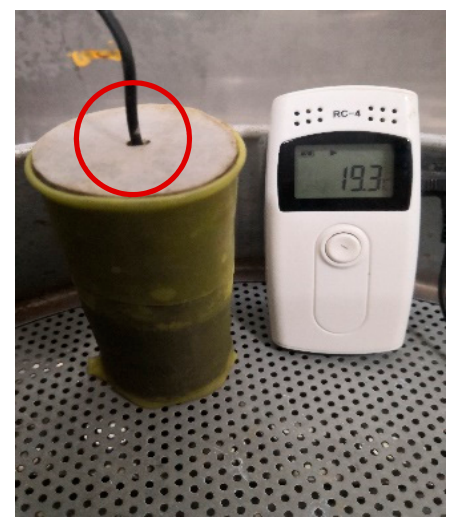

(b)

Figure 7. Differences in probe placement (a) Thermal detector used in [27]; (b) Thermal detector used in this paper.

The super-cooling stage [28], circled in yellow in Figure 5, indicates a sharp drop in temperature at the beginning of the freezing process, found in the test data from [20]. However, unlike the partially exposed probe in [28] (Figure 8a), the whole probe was buried (Figure 8b) to allow measurement of the internal temperature of the samples every $15 \mathrm{~min}$. Supercooling and nucleation only take place at the product surface in contact with the refrigerant [29]; similar to the cooling curves in reference [30], the super-cooling stage could not be detected in this test. (Figure 8c). 


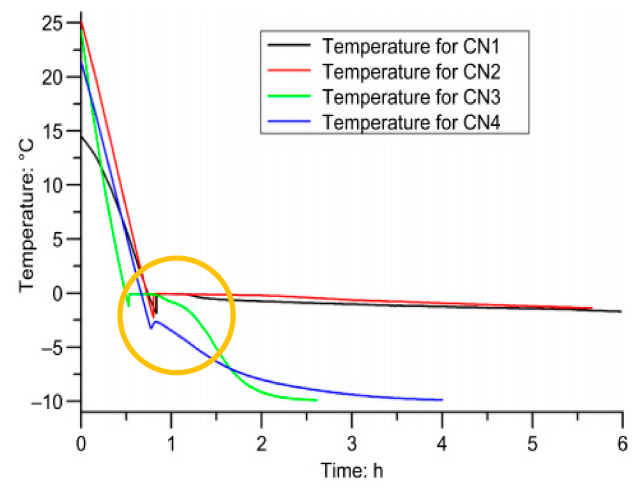

(a)

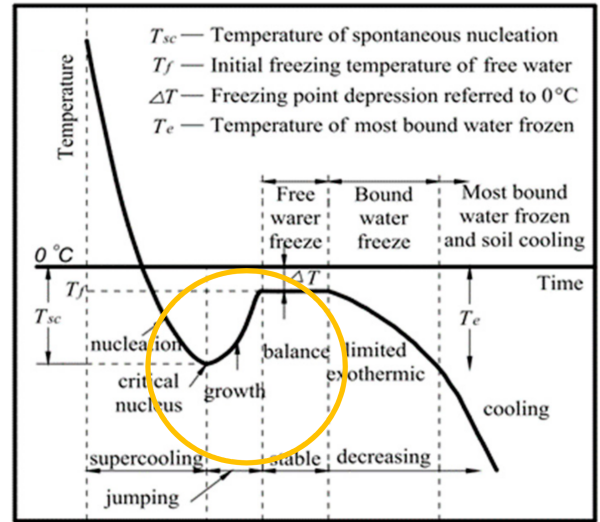

(b)

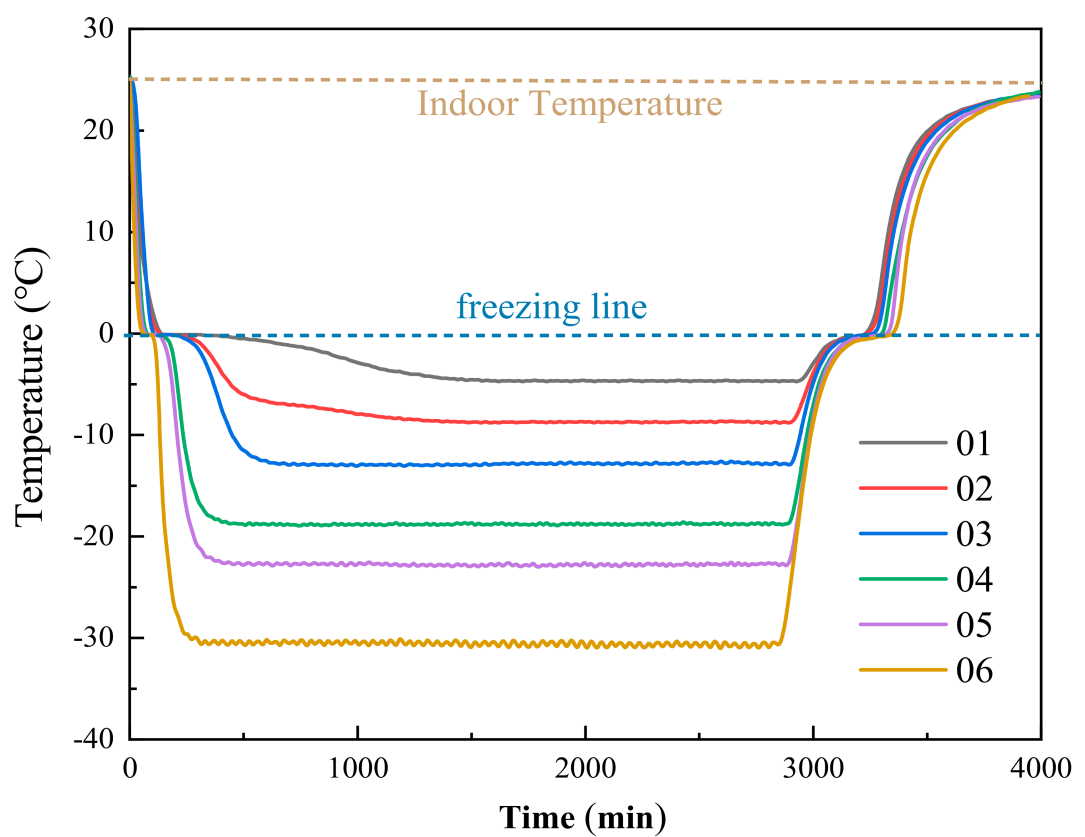

(c)

Figure 8. Typical cooling curves for frozen soil: (a) Typical cooling curve in [28]; (b) Typical cooling curve in [3]; (c) Low-temperature test chamber.

Figure $8 \mathrm{c}$ shows the results of the temperature record of the soil samples. Due to instrument error and temperature compensation differences, the internal temperature of the soil was found to be slightly different from the set temperature. A platform was visible near the freezing point [31] at the beginning of the freezing process. The phase transition of water to ice is an exothermic process. When the crystallization process is completed, the temperature is maintained at the inflection point of the set temperature. Freezing temperature has a close influence on the turning point in freezing action, and a linear relationship with plateau time.

Freezing plateau time has a closer relationship with freezing temperature than thawing plateau time. This is because the exothermic effect of freezing delays the time taken to reach a higher temperature target. In addition, the freezing progress has a smaller temperature difference between $0{ }^{\circ} \mathrm{C}$ and the target temperature. Slow crystallization (01 sample in Figure 8c) and rapid crystallization (02-06 samples in Figure 8c) were both observed during freezing, indicating that when soil temperature reaches a certain value, it is difficult for molecules to overcome the energy barrier and enter the nuclei. 


\section{Pore Distribution in Frozen-Thawed Undisturbed Soil under Different Temperatures}

\subsection{Effects of Freeze-Thaw Action}

As Figure 9 shows, the undisturbed soil has good uniformity and little specificity. A main peak was seen, indicating that the tiny pores indicate the primary pore distribution of soft marine clay. The average value of the main peak was about $9 \%$, while that of the subpeak was about $0.2 \%$. The number of tiny pores was 45 times larger than that of the medium pores.

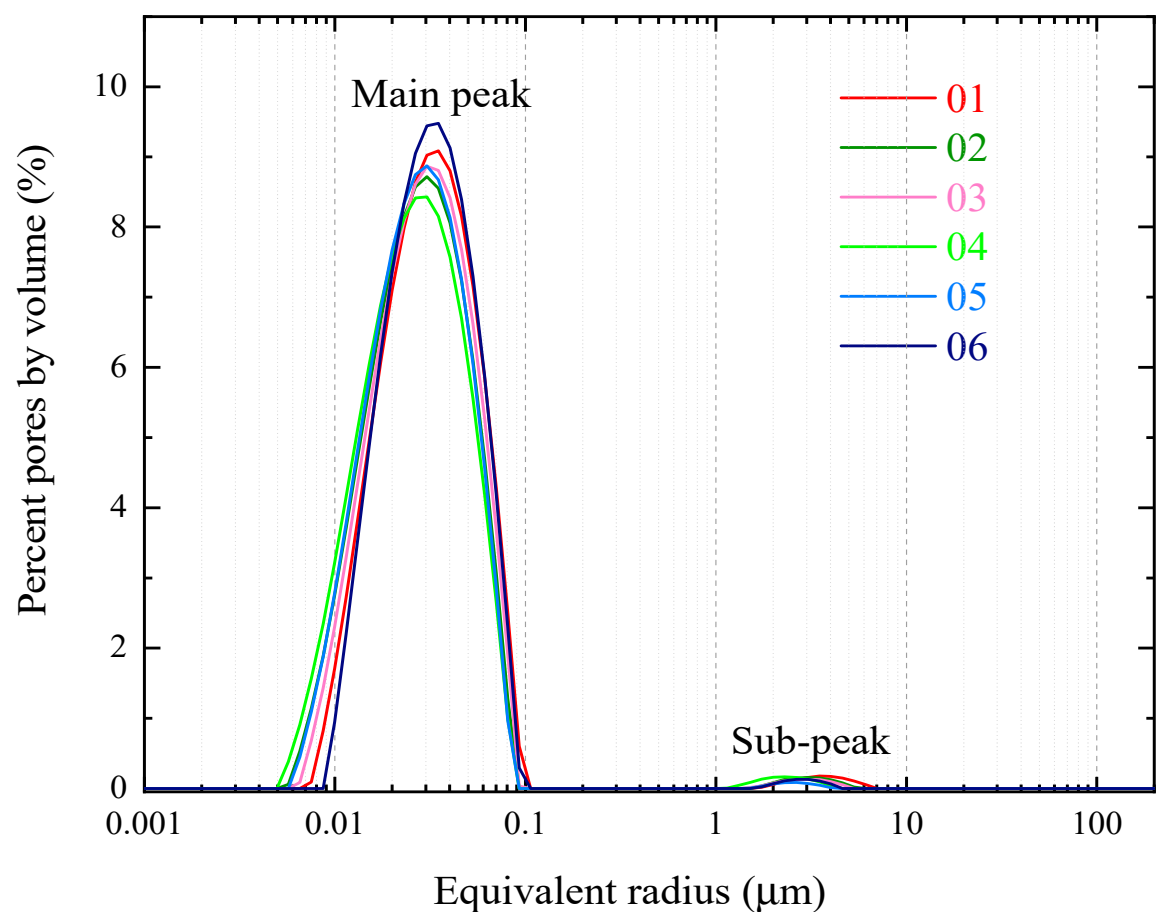

Figure 9. Pore distribution of undisturbed soil before freezing.

As Figure 10 shows, after freezing, the percentage of small pores decreased by about $1 \%$, while the percentage of medium pores increased. Furthermore, an end peak appeared from the frost heaving of the soil water. Due to the different freezing temperatures of the six samples, the change in pores is different. For the $-5^{\circ} \mathrm{C}$ frozen soil sample (black line) in Figure 10, the subpeak value of the soil sample was different from the other five samples by an order of magnitude owing to the presence of a turning point between $-5{ }^{\circ} \mathrm{C}$ and $-10{ }^{\circ} \mathrm{C}$, a thermodynamic association. Because of the frost process, the main peak declined, the subpeak moved left, and an end peak appeared. 


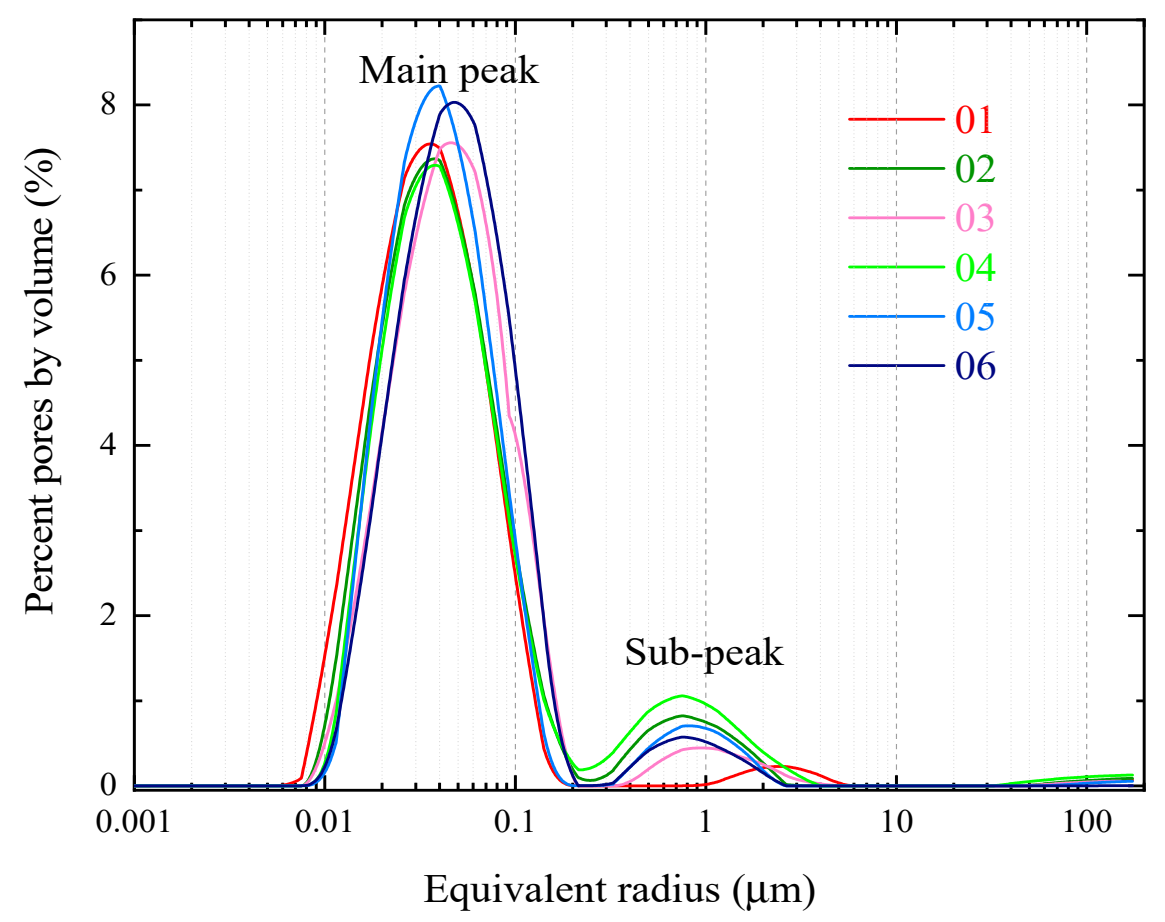

Figure 10. Pore distribution of undisturbed soil after freezing.

\subsection{Effects of Freeze Temperature}

Freeze temperature has the greatest influence on frozen soil, producing different levels of axis movement, as shown in Figure 8.

From Figure 11a-f, it is clear that the main peak has moved to the right with change in distance, the value of the main peak has declined, and the projection of the main peak on the horizontal axis has increased. At the same time, the subpeak increased sharply and moved to the left. For the $-5{ }^{\circ} \mathrm{C}$ frozen soil (Figure 11a), the axis movement of the main peak was much lesser than that of the other five soil samples, as was the increase in the subpeak value. The average decrease in main peak value of the frozen soil samples was about $20 \%$, reflecting the percentage of tiny pores turned to medium pores. Almost all of the subpeaks of the thawed soil came from the enlarged tiny pores, and the subpeak value of the thawed soil was triple or even quadruple the unfrozen one. Furthermore, partial medium pores of the unfrozen soil gained volume and connected with nearby pores to form large ones, explaining the appearance of the end peak after freezing. The larger the subpeak value of the unfrozen soil, the more obvious the end peak. 

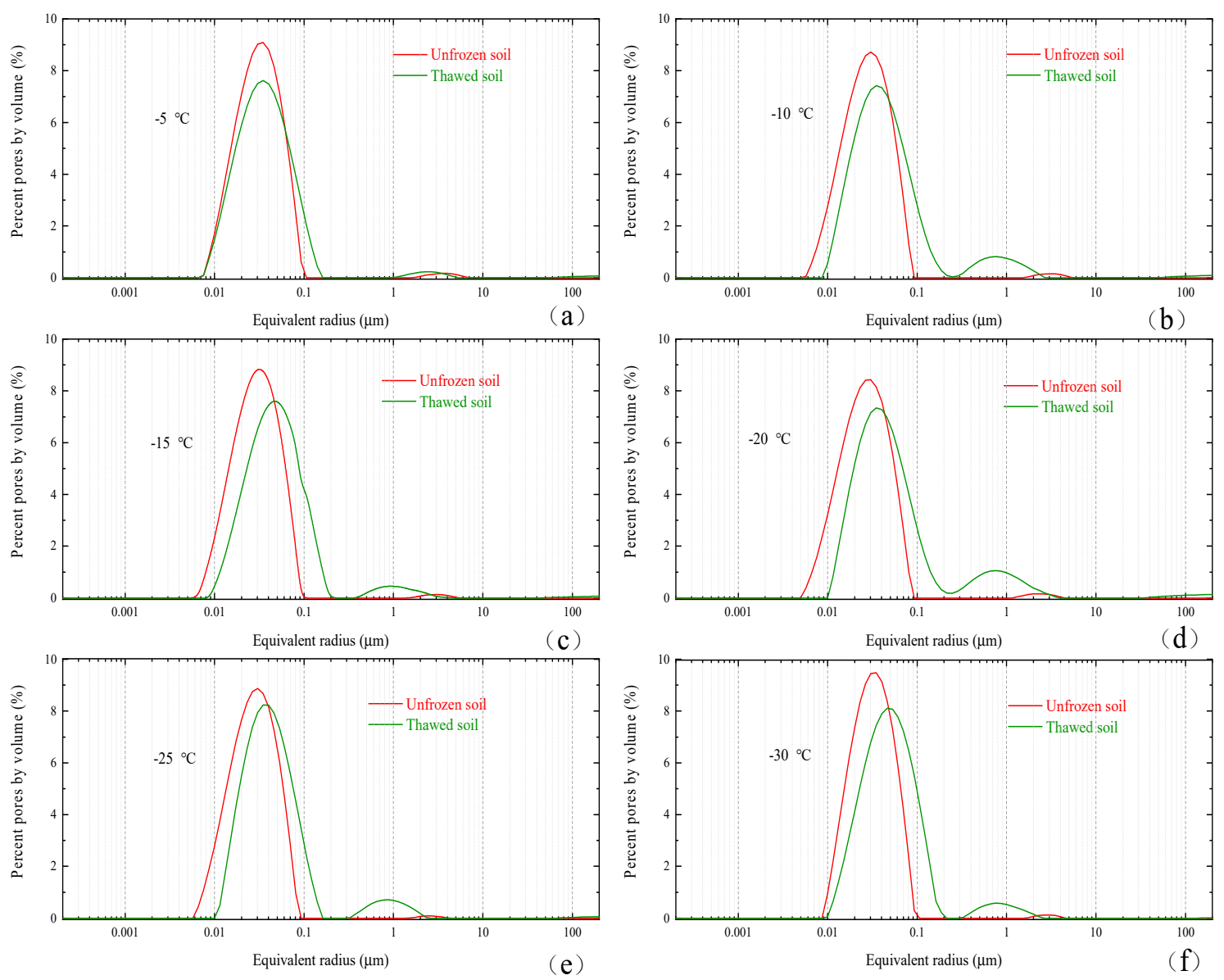

Figure 11. Pore distribution of soil before and after freezing: (a) Distribution of pore size before and after freezing at $-5^{\circ} \mathrm{C}$; (b) Distribution of pore size before and after freezing at $-10{ }^{\circ} \mathrm{C}$; (c) Distribution of pore size before and after freezing at $-15^{\circ} \mathrm{C} ;(\mathbf{d})$ Distribution of pore size before and after freezing at $-20{ }^{\circ} \mathrm{C}$; (e) Distribution of pore size before and after freezing at $-25^{\circ} \mathrm{C}$; (f) Distribution of pore size before and after freezing at $-30^{\circ} \mathrm{C}$.

Thus, it is evident that all the soil pore sizes tended to increase after freezing. In general, the lower the temperature, the more obvious the uptrend. The temperature had little influence on pore size below $-10^{\circ} \mathrm{C}$.

\subsection{Changes in Pore Size Distribution}

The percentage change in diameter of the pores is shown in Figure 12. The vertical axis represents the difference in value between unfrozen soil and thawed soil, with the negative values signifying a decrease, and the positive ones an increase, with corresponding diameter. As the temperature dropped, the number of pores with diameter between $0.003 \mu \mathrm{m}$ and $0.05 \mu \mathrm{m}$ decreased and formed a main trough. At the same time, pores with diameter between $0.05 \mu \mathrm{m}$ and $0.2 \mu \mathrm{m}$ increased to form a main peak. It is quite clear that the increase of the main peak was a result of the reduction-pores with $0.02 \mu \mathrm{m}$ average diameter went through expansion of pore water to turn into pores with $0.1 \mu \mathrm{m}$ average diameter. The frost heave rate of pore water is much higher than that of free water, and the change in diameter was 40 times the volume change of the water that turned into ice. The freezing action significantly affected pores with $0.1 \mu \mathrm{m}$ diameter. A plateau was seen between $0.2 \mu \mathrm{m}$ and $0.4 \mu \mathrm{m}$, determined by the initial pore distribution of soil and representing the coincidence of the two curves in Figure 12. Because the undisturbed soil was not completely homogeneous, the plateau was not particularly related to temperatures below $-10{ }^{\circ} \mathrm{C}$ but closely related to the number of initial small 
pores. The second peak focused on diameters between $0.2 \mu \mathrm{m}$ and $2 \mu \mathrm{m}$, the peak value of which was a third of that of the main peak. Considering that the pore size of the subpeak was nearly 10 times that of the main peak, the engineering properties of soil could be badly affected. Essentially, no pores were found in the undisturbed soil at the location of the second peak. An unexpected subtrough $(2-7 \mu \mathrm{m})$ appeared after the subpeak, because the expansion of the tiny pores in the undisturbed soil was unable to reach the size of the medium pores. The medium pores in the undisturbed soil swelled due to the freezing effect, after which an end peak larger than $30 \mu \mathrm{m}$ was formed. Notably, the diameter of the medium pores of the undisturbed soil was almost 100 times larger.

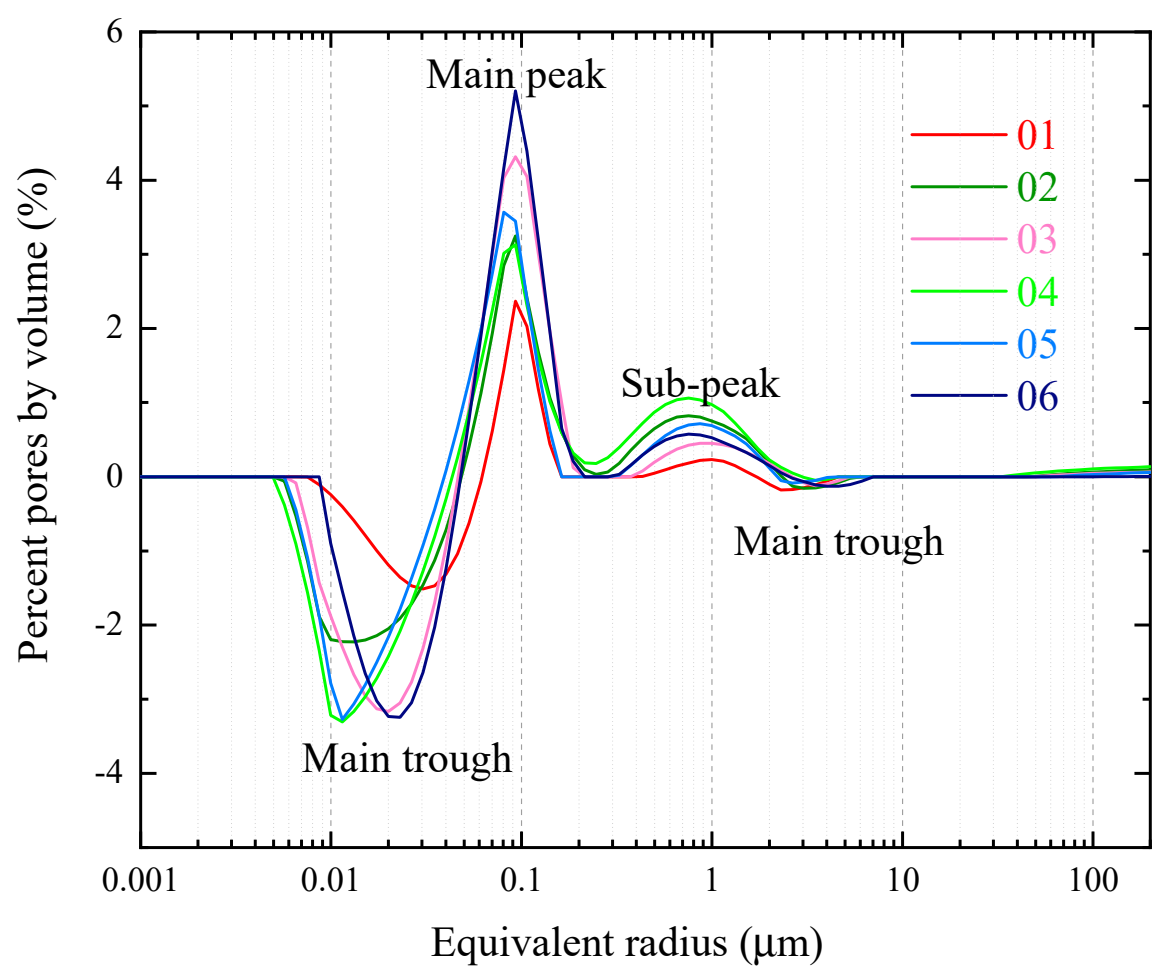

Figure 12. Changes to pore distribution before and after freezing.

For the 0.1 sample shown in Figure 12, pore changes were limited by temperature. A temperature of $-5{ }^{\circ} \mathrm{C}$ was not enough to freeze weakly bound water. At temperatures between $-10{ }^{\circ} \mathrm{C}$ and $-30{ }^{\circ} \mathrm{C}$, the difference in freezing strongly bound water was too small to be clearly observed. Overall, all pores in the undisturbed soil tended to expand, with the small pores expanding nearly 10 times and the medium pores expanding nearly 100 times.

\subsection{Distribution of Pore Throat}

As Figure 13 shows, the percentage of specific-sized pores among the total number of pores is accurately quantified. Pores with a diameter of $0-0.1 \mu \mathrm{m}$ accounted for more than $90 \%$, a figure that reached $99 \%$ before freezing. Thus, tiny pores occupied the most important position, irrespective of the freezing temperature was. After freezing, the percentage of pores of diameter 0.1-1.6 $\mu \mathrm{m}$ and $0.63-1 \mu \mathrm{m}$ increased to $5 \%$ and the percentage of pores of diameters $0.4-0.63 \mu \mathrm{m}$ and $1-1.6$ increased to $2 \%$. Furthermore, the increment of the $-5^{\circ} \mathrm{C}$ frozen sample was far less than the others. Overall, the freezing action turned $9 \%$ of the tiny pores into larger pores from a microscopic point of view. 


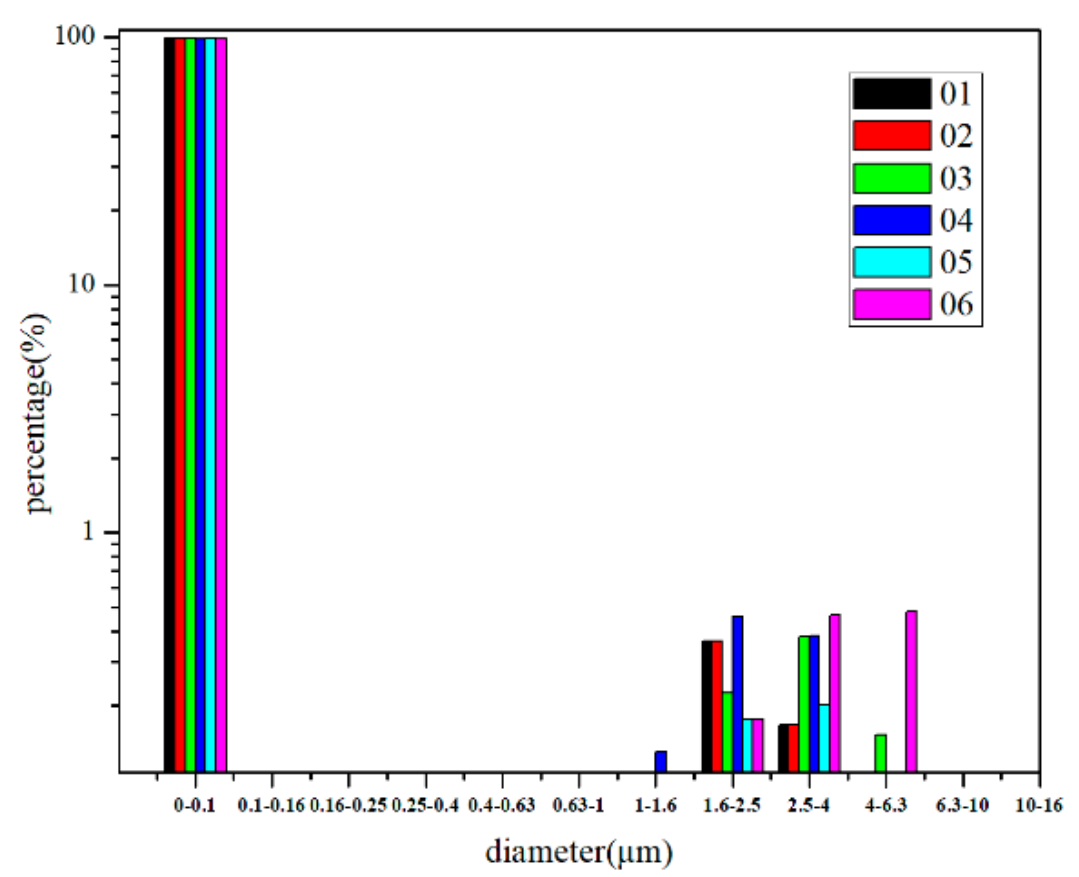

(a)

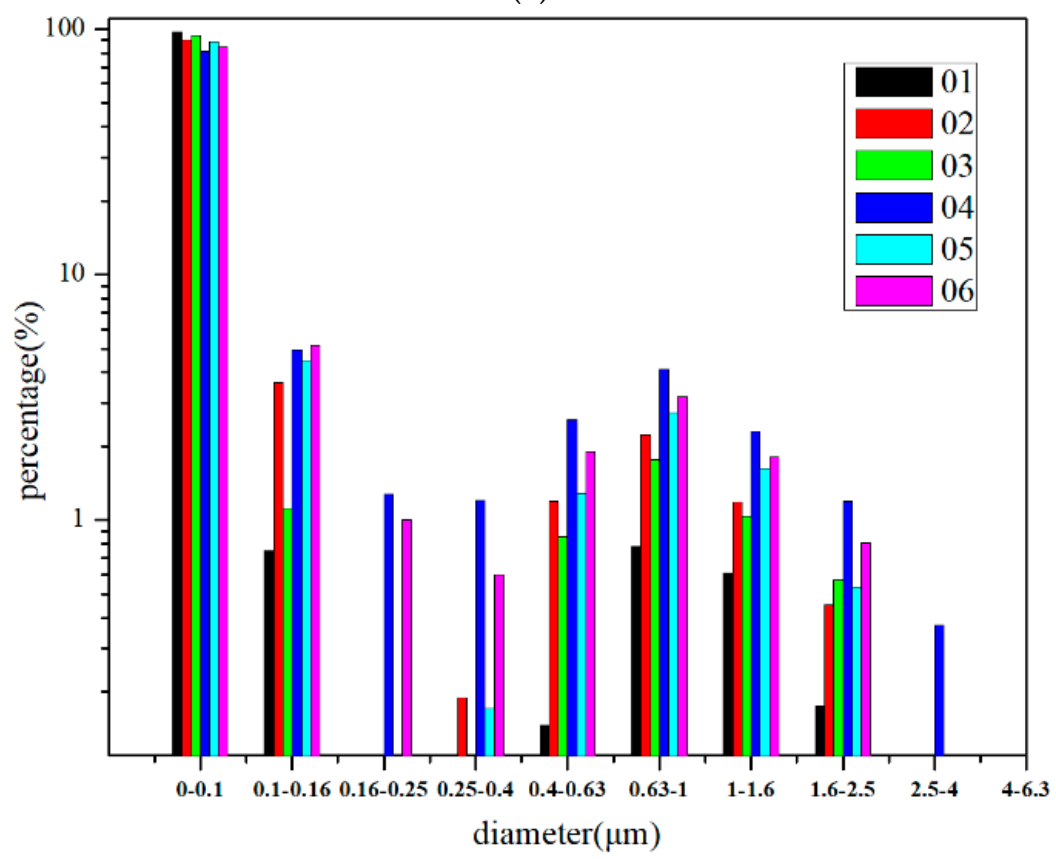

(b)

Figure 13. Pore throat before and after freezing: (a) Distribution of pore throat before freezing; (b) Distribution of pore throat after freezing.

\section{Pore Distribution of V-R Soil at Different Temperatures}

From the above analysis, it is clear that the influence of temperature is particularly obvious above $-10{ }^{\circ} \mathrm{C}$. Temperatures above the cold medium temperature exist simultaneously in the freezing construction stage (Figure 14). The samples were set and tested at $-1{ }^{\circ} \mathrm{C},-2{ }^{\circ} \mathrm{C},-5{ }^{\circ} \mathrm{C},-8{ }^{\circ} \mathrm{C}$, and $-20^{\circ} \mathrm{C}$ for $0 \mathrm{~h}, 1 \mathrm{~h}, 2 \mathrm{~h}, 3 \mathrm{~h}, 4 \mathrm{~h}, 6 \mathrm{~h}$, and $12 \mathrm{~h}$ after freezing. When the freezing time reached $24 \mathrm{~h}$, the soil sample was thawed in a constant-temperature humidity chamber. 


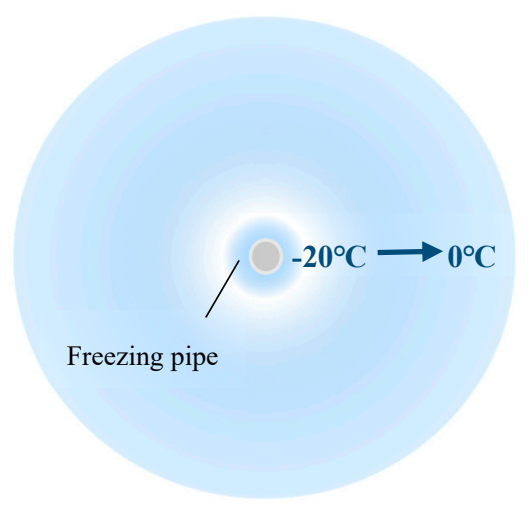

Figure 14. Schematic diagram of temperature reduction.

There were three types of water in the clay: free water, film water (loosely bound water), and strong bound water. The crystallization temperature of soil water is strongly associated with its type. In Figure 15 , because $-1{ }^{\circ} \mathrm{C}$ was not enough to freeze the water in the tiny pores, the main peaks of seven curves overlapped. The medium pores of the frozen soil slightly increased in the first hour and lasted for $24 \mathrm{~h}$ afterward; thus, the temperature a little below the freezing point rapidly froze the partially free water on the soil surface.



Figure 15. Distribution of pore size for different freezing times at $-1{ }^{\circ} \mathrm{C}$.

Water nucleates before it freezes, and volume tends to expand during nucleation. Water signals cannot be detected once frozen. As Figure 16 shows, $-3{ }^{\circ} \mathrm{C}$ freezing temperature made a bigger difference than $-1{ }^{\circ} \mathrm{C}$. The value of the main peak decreased over time, with the most pronounced drop being seen in the first hour. After the first $4 \mathrm{~h}$, the value of the subpeak increased because of the water swelling, and then the subpeak value went down gradually as a result of signal attenuation. After thawing, the subpeak of the thawed curve shifted to the left. The left change was because the $-3^{\circ} \mathrm{C}$ temperature was able to partially freeze the bottom of the soil sample where it made contact with the refrigerator. The volume increment was offset by self-weight consolidation. 


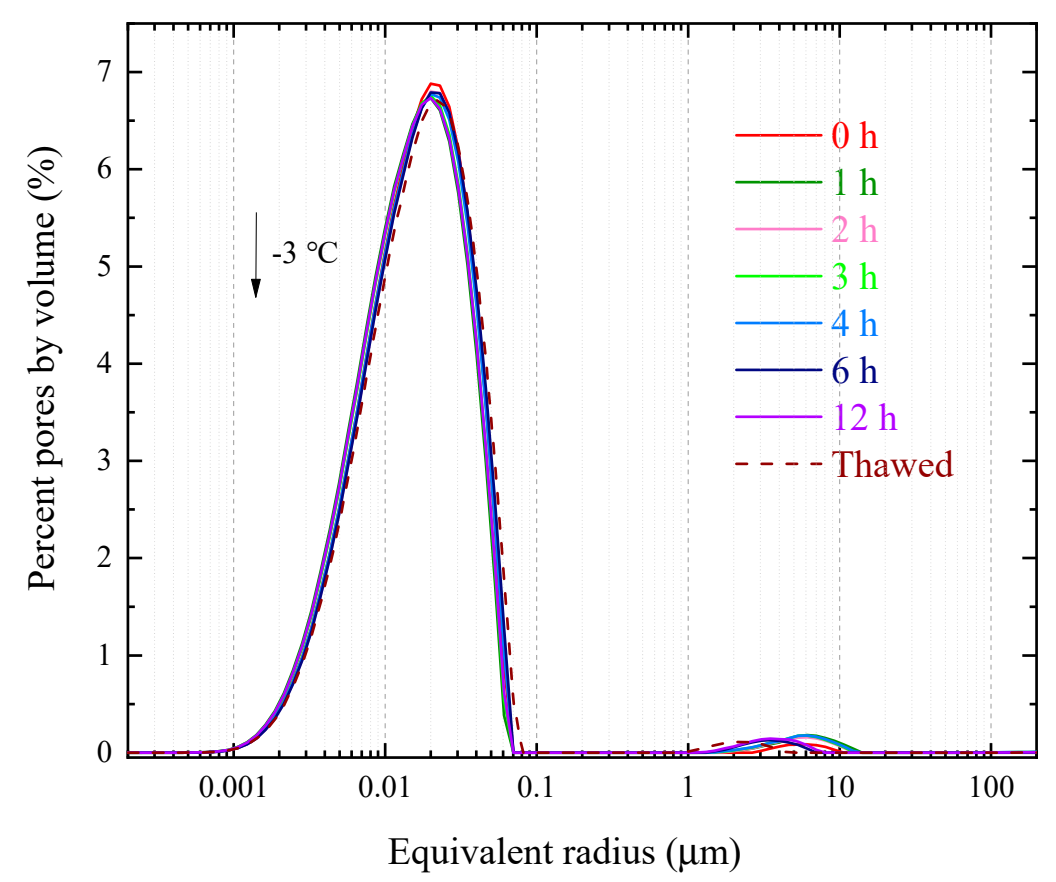

Figure 16. Distribution of pore size for different freezing times at $-3{ }^{\circ} \mathrm{C}$.

Figure 17 shows the percentage change of the $-5{ }^{\circ} \mathrm{C}$ frozen soil, which had a more obvious change than the two samples previously discussed. After the first $6 \mathrm{~h}$, the value of the main peak fell slowly under the freezing effect. However, a reverse trend was seen after $12 \mathrm{~h}$ of freezing, which the authors attribute to partial freezing of the water in the medium pores; this resulted in some of the water in the medium pores being identified as water in tiny pores. Subpeak value increased at first but then decreased with time to a degree more evident than that in the $-3{ }^{\circ} \mathrm{C}$ frozen soil, for the same reason. Contrasting the thawed curve (brown dotted line) with the $12 \mathrm{~h}$ curve indicates that the latter was not enough to complete the whole freezing possess in the $-5{ }^{\circ} \mathrm{C}$ frozen soil.

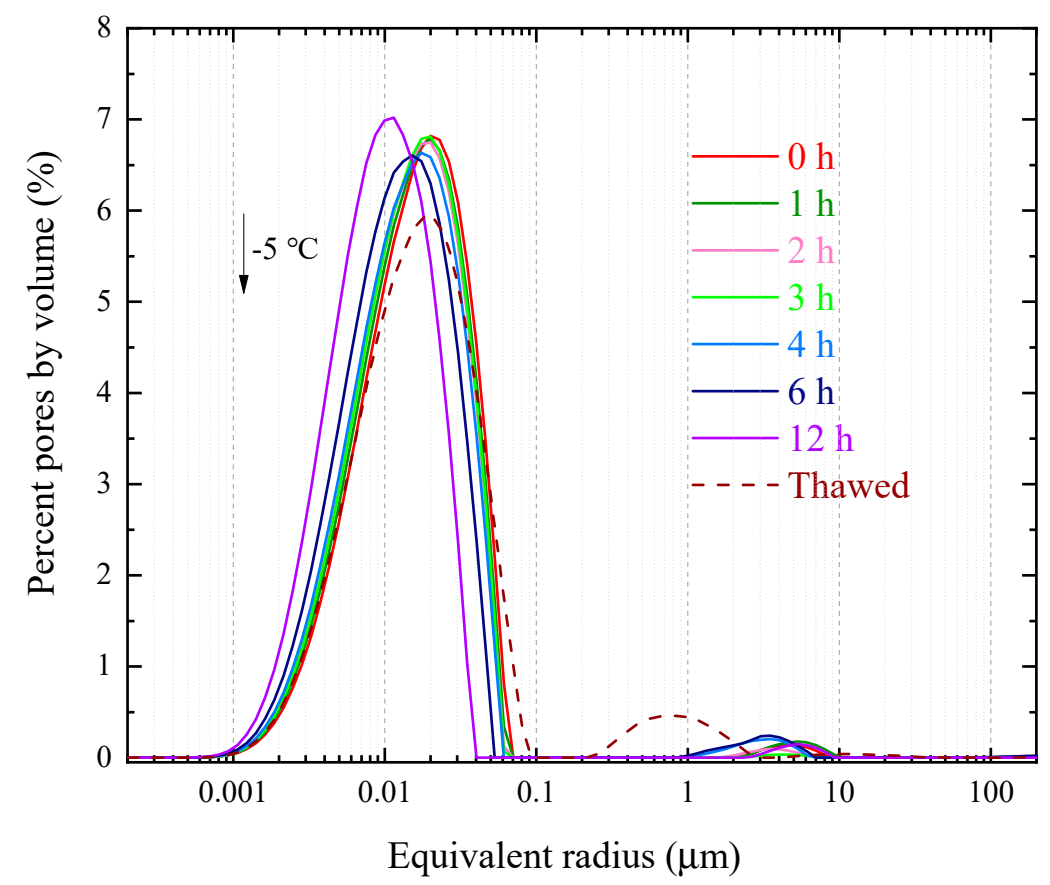

Figure 17. Distribution of pore size for different freezing times at $-5{ }^{\circ} \mathrm{C}$. 
In Figure 18, the trend by which the value of the main peak increased after going down was more obvious than that for the $-5^{\circ} \mathrm{C}$ frozen value seen in Figure 17. The downturn process of the main peak was completed in $2 \mathrm{~h}$, indicating that the freezing rate greatly increased, as compared to that for the $-5{ }^{\circ} \mathrm{C}$ frozen sample. In the first $2 \mathrm{~h}$, the reduction in the main peak was simultaneous with the left movement of the subpeak, because the water in the tiny pores froze slowly and the medium pores were identified as small ones. After $2 \mathrm{~h}$, the water in the medium pores were partially detected as being in tiny pores, so the apparent number of tiny pores increased. It can be reasoned that for $-8{ }^{\circ} \mathrm{C}$ frozen soil, the freezing rate of water in medium pores was faster than for the tiny pores.

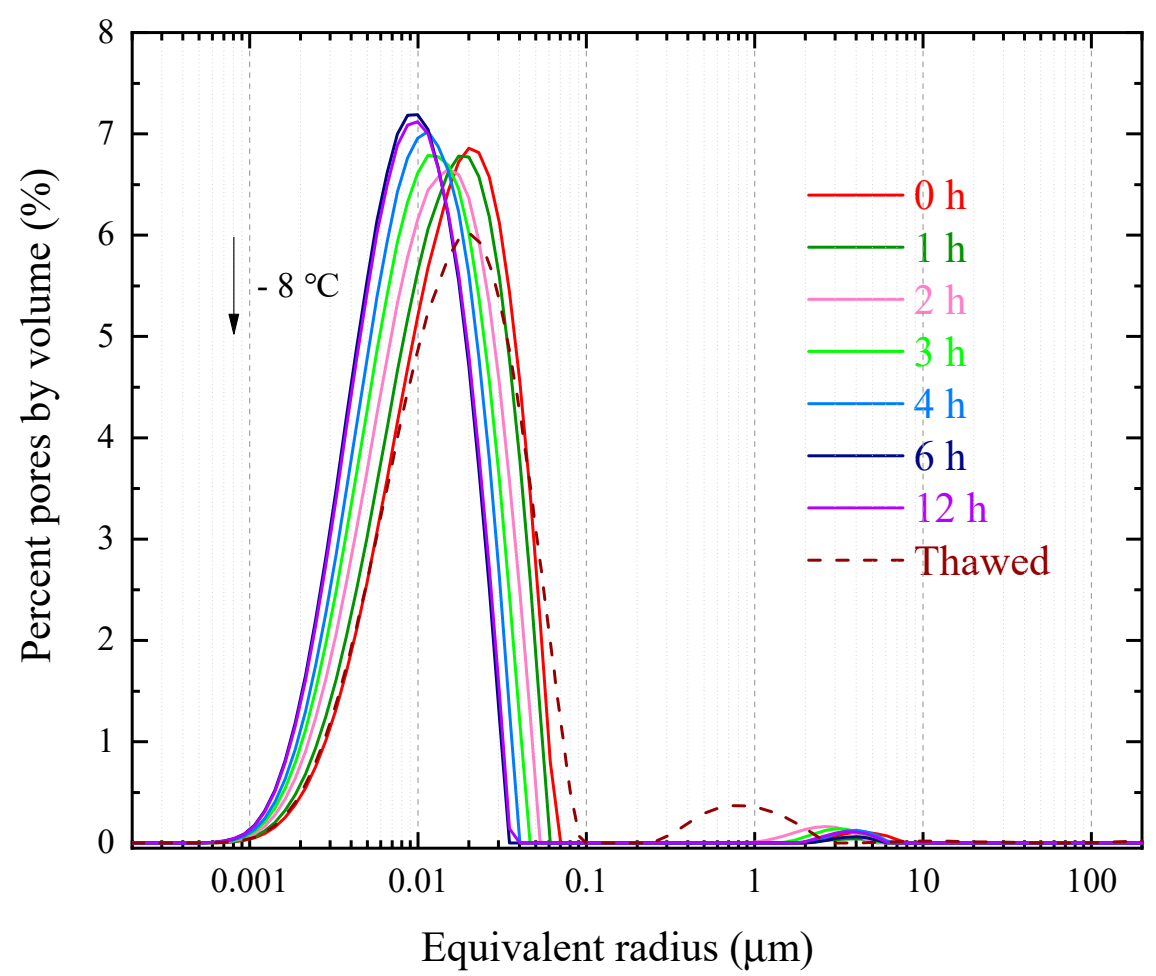

Figure 18. Distribution of pore size for different freezing times at $-8{ }^{\circ} \mathrm{C}$.

As Figure 19 shows, the trend wherein the main peak value rose after falling was not evident below certain temperatures. At $-20^{\circ} \mathrm{C}$, the difference between the freezing rate of tiny pores and medium pores was negligible. With time, the number of tiny pores declined and the medium pores shrank to a tenth of their initial size. Ninety-five percent of the freezing process was completed in the first $12 \mathrm{~h}$ for the $-20^{\circ} \mathrm{C}$ frozen soil. 


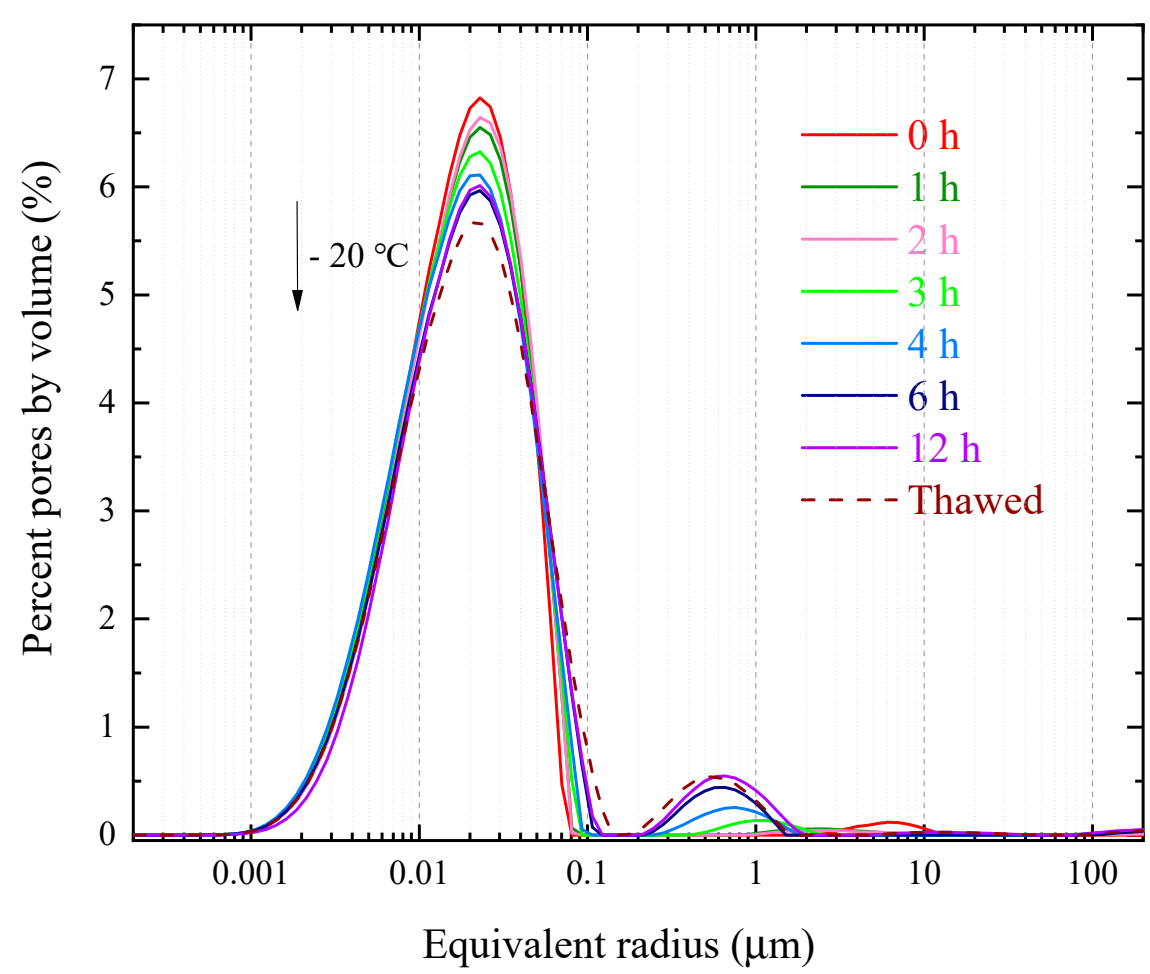

Figure 19. Distribution of pore size for different freezing times at $-20^{\circ} \mathrm{C}$.

From the foregoing figures, it is clear that freezing rate is closely related to temperature, especially for temperatures above $-10{ }^{\circ} \mathrm{C}$, with percentage changes of pores at different times reflecting the freezing process.

\section{Pore Distribution in Vacuum Preloading Remolded Soil at Different Freezing Speeds}

Freezing speed is an important factor in water crystallization, as the freezing action forms a temperature field [32]. In the actual freezing process, the soil close to the pipe freezes more quickly than the soil around it (Figure 20). The soil in the middle of the frozen range is both the refrigerant and the insulation layer for the outer soil. To explore the effect of freezing speed on porosity, three soil samples were subjected to different freezing speeds.

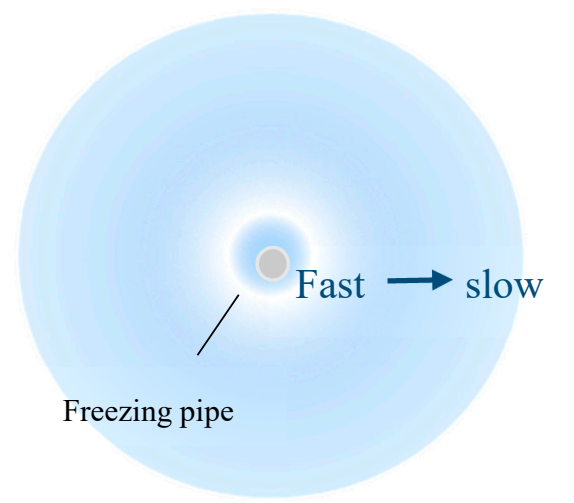

Figure 20. Schematic diagram of freezing speed reduction.

The following method was used to simulate different freezing speeds. For fast freezing speed, soil sample 15 (black line in Figure 21a) was put into the low-temperature test box after the temperature dropped to $-20^{\circ} \mathrm{C}$. The middle freezing speed soil sample, numbered 16 (pink line in Figure 21a), was put into the low-temperature test box at indoor temperatures, after which the equipment was 
switched on to reduce the temperature. To achieve a low freezing speed, thermal insulation material was used to cover sample 17 (blue line in Figure 21a), which was then frozen in the same way as sample 16.

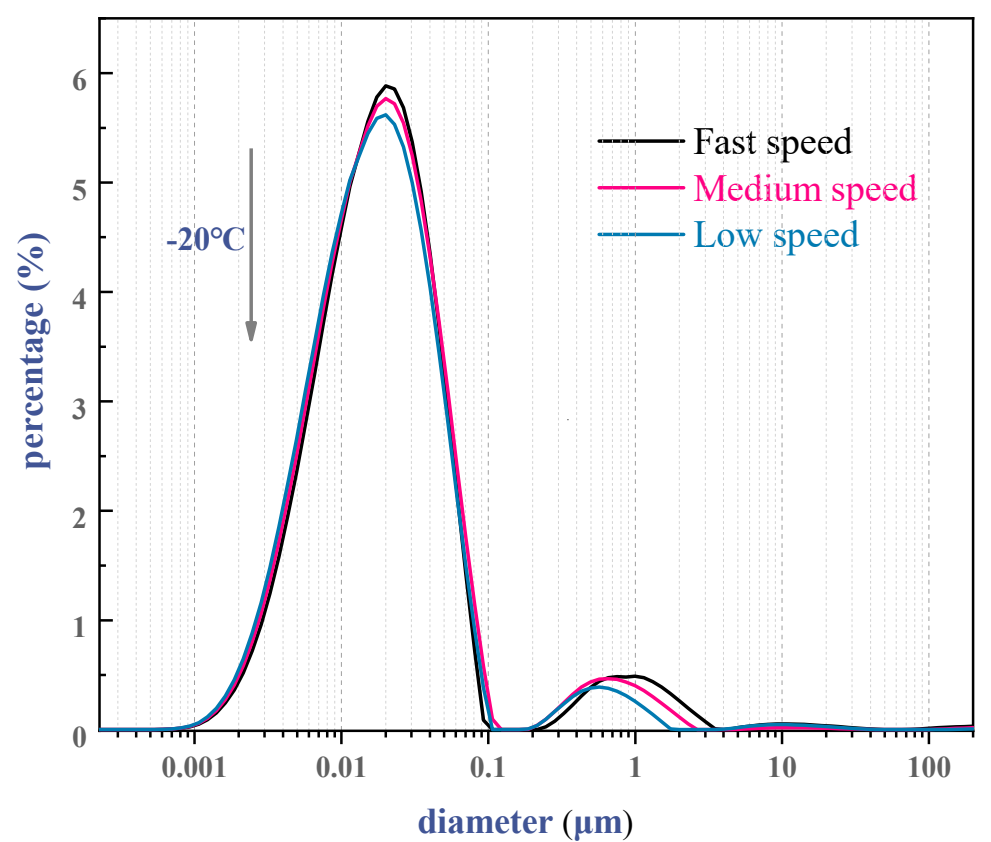

(a)

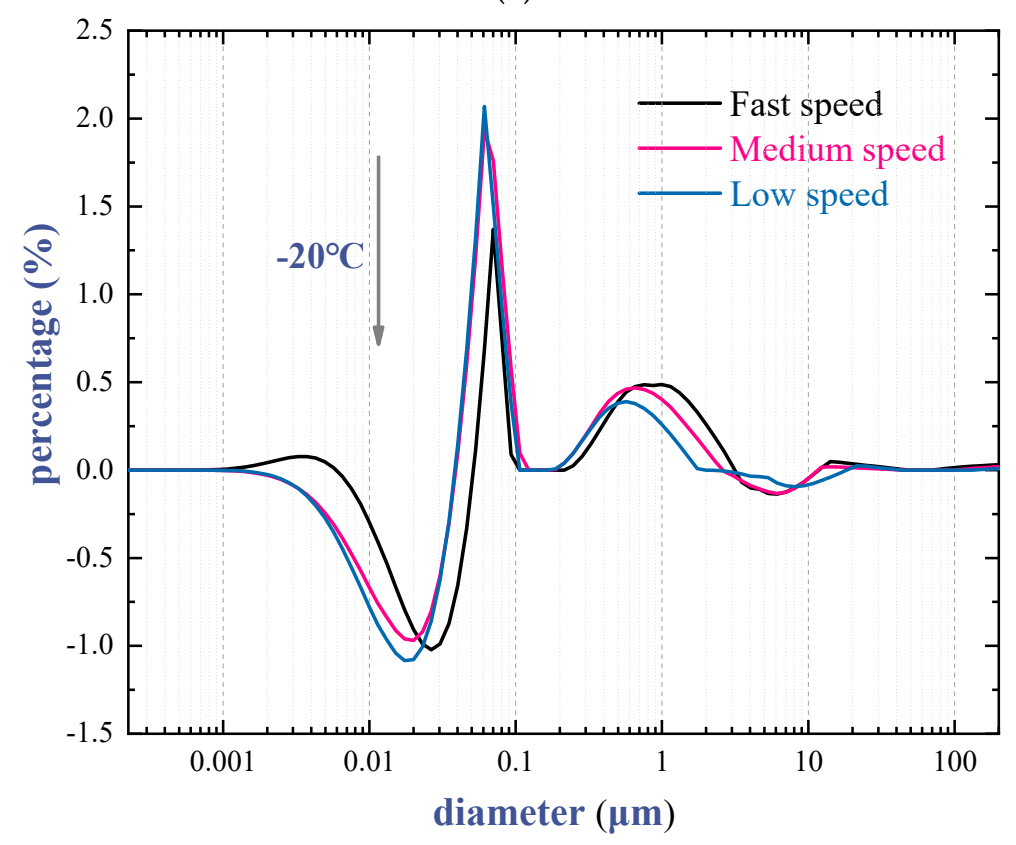

(b)

Figure 21. Distribution of pore size at different freezing speeds: (a) Distribution of pore size at different freezing speeds; (b) Distribution of pore size change at different freezing speeds.

From the results obtained by freezing the three soil samples at $-20{ }^{\circ} \mathrm{C}$, but at different speeds (Figure 21a), the differences are obvious. The faster the freezing speed, the larger the value of the main peak and the subpeak. The slower the freezing speed, the greater the distance before the subpeak turned left. During the change from liquid to solid, the voids in the water increased, thereby increasing volume. Figure $21 \mathrm{~b}$ shows that void volume is related to freezing speed. The faster the freezing speed, the greater the final void volume. The low freezing speed allowed all the water in the tiny pores to 
freeze. The influence of fast freezing speed was greatest on medium pores, whereas low freezing speed had a greater effect on tiny pores. Because medium pores have a greater influence on soil characteristics, soil deformation at the edge of the frozen area was less than in the center of the soil.

\section{Conclusions}

There are three types of water in soil pores: strong bound water, osmotic bound water, and free water. The difficulty in water crystallization is related to the chemical bond between water molecules and soil particles. Bound water on the surface of the soil particles is controlled by electrostatic attraction between the particles and the water molecules; thus, not all water in the pores can be frozen. To a certain degree, tiny pores have more strong bound water than medium pores; this is, however, dependent on specific surface area. It can be concluded that the freezing action causes greater destruction on medium pores than tiny pores. The freezing process of water in saturated soil is affected by several factors, two of them -freezing temperature and freezing speed-were researched in this paper. The macro process of temperature variation is closely related to its microscopic process. Using NMR technology, microstructural changes in soil were observed, offering several conclusions:

- Time taken to reach a set temperature has a linear relation with temperature: The lower the set temperature, the less time required to reach the target temperature. This is because the heat generated by crystallization changes subtly below $-10^{\circ} \mathrm{C}$ : The lower the set temperature, the faster the heat loss.

- Under freezing action, the number of tiny pores decreases but the number of medium pores increases, with even large pores appearing. Finally, the void ratio of the soil also rises.

- All sizes of undisturbed soil pores tend to increase under different freezing temperatures. In general, the lower the temperature, the more obvious the uptrend. For temperatures below $-10{ }^{\circ} \mathrm{C}$, it is difficult for pore changes to exceed a fixed value.

- During the early stages of the freezing process, the percentage of tiny pores increases, but then slows down, because there is more free water in medium pores than in small pores; thus, the water in medium pores freezes earlier than that in the small pores. As the temperature drops, this process accelerates.

- The medium pores in the soil samples make a major contribution to the failure of soil structure.

- Fast freezing speed has a greater effect on medium pores, but slow freezing speed has a greater effect on tiny pores. Because medium pores have a greater effect on porosity, the faster the freezing speed, the greater the ultimate void ratio. Thus, even at the same freezing temperature, changes in soil pores far from the freezing pipe are smaller than those near it.

Author Contributions: Conceptualization, Z.D. and B.K.; investigation, F.X. and B.Y.; resources, T.X.; writing-original draft preparation, B.K.; writing_review and editing, Z.D.; supervision, T.X.; funding acquisition, Z.D. All authors have read and agreed to the published version of the manuscript.

Funding: This research was funded by the Chinese National Natural Science Foundation (51508506); Joint Fund of Zhejiang Provincial Natural Science Foundation Hangzhou Science (LHZ20E080001); Hangzhou Technology Plan Project (20172016A06, 20180533B06, 20180533B12, 20191203B44), and The Science and Technology Development Fund, Macau SAR (File no. SKL-IOTSC-2018-2020).

Conflicts of Interest: The authors declare no conflict of interest.

\section{References}

1. Lackner, R.; Amon, A.; Lagger, H. Artificial ground freezing of fully saturated soil: Thermal problem. J. Eng. Mech. 2005, 131, 211-220. [CrossRef]

2. Liu, J.; Zhang, X.; Zhang, H. Experimental study on the dynamic characteristic of soft soil under cyclic loads. J. Highw. Transp. Res. Dev. 2014, 8, 18-26. [CrossRef]

3. Huang, Z.; Fu, H.; Zhang, J.; Chen, W.; Shi, Y. Structural damage evaluation method for metro shield tunnel. J. Perform. Constr. Facil. 2019, 33, 1. [CrossRef] 
4. Casini, F.; Gens, A.; Olivella, S.; Viggiani, G.M.B. Artificial ground freezing of a volcanic ash: Laboratory tests and modelling. Environ. Geotech. 2016, 3, 141-154. [CrossRef]

5. Zhang, M.; Lu, J.; Lai, Y.; Zhang, X. Variation of the thermal conductivity of a silty clay during a freezing-thawing process. Int. J. Heat Mass Transf. 2018, 124, 1059-1067. [CrossRef]

6. Kruse, A.M.; Darrow, M.M. Adsorbed cation effects on unfrozen water in fine-grained frozen soil measured using pulsed nuclear magnetic resonance. Cold Reg. Sci. Technol. 2017, 142, 42-54. [CrossRef]

7. Alhire, B.D. The mechanical behaviour of frozen earth materials under high pressure triaxial test conditions: A note on a plasticity solution to the stability of slopes in inhomogenous clays. Géotechnique 1972, 23, 136-137.

8. Da Re, G.; Germaine, J.T.; Ladd, C.C. Triaxial testing of frozen sand: Equipment and example results. J. Cold Reg. Eng. 2003, 17, 90-118. [CrossRef]

9. Pimentel, E.; Sres, A.; Anagnostou, G. Large-Scale laboratory tests on artificial ground freezing under seepage-flow conditions. Géotechnique 2012, 62, 227-241. [CrossRef]

10. Mei, C.C.; Peder, A. Thermal consolidation of thick and soft soil layer. J. Eng. Mech. 1988, 114, 990-1010. [CrossRef]

11. Wang, C.; Lai, Y.; Yu, F.; Li, S. Estimating the freezing-thawing hysteresis of chloride saline soils based on the phase transition theory. Appl. Therm. Eng. 2018, 135, 22-33. [CrossRef]

12. Caicedo, B. Physical modelling of freezing and thawing of unsaturated soils. Géotechnique 2009, 2, 106-126. [CrossRef]

13. Zhou, J.; Tang, Y. Practical model of deformation prediction in soft clay after artificial ground freezing under subway low-level cyclic loading. Tunn. Undergr. Space Technol. 2018, 76, 30-42. [CrossRef]

14. Amiri, E.A.; Craig, J.R.; Kurylyk, B.L. A theoretical extension of the soil freezing curve paradigm. Adv. Water Resour. 2018, 111, 319-328. [CrossRef]

15. Zhou, J.; Tang, Y. Experimental inference on dual-porosity aggravation of soft clay after freeze-thaw by fractal and probability analysis. Cold Reg. Sci. Technol. 2018, 153, 181-196. [CrossRef]

16. Kozlowski, T. A simple method of obtaining the soil freezing point depression, the unfrozen water content and the pore size distribution curves from the DSC peak maximum temperature. Cold Reg. Sci. Technol. 2016, 122, 18-25. [CrossRef]

17. Bai, R.; Lai, Y.; Zhang, M.; Yu, F. Theory and application of a novel soil freezing characteristic curve. Appl. Therm. Eng. 2018, 129, 1106-1114. [CrossRef]

18. Chai, M.; Zhang, J.; Zhang, H.; Mu, Y.; Sun, G.; Yin, Z. A method for calculating unfrozen water content of silty clay with consideration of freezing point. Appl. Clay Sci. 2018, 161, 474-481. [CrossRef]

19. Wang, J.; Nishimura, S.; Okajima, S.; Joshi, B.R. Small-Strain deformation characteristics of frozen clay from static testing. Géotechnique 2018, 69, 1-34. [CrossRef]

20. Lai, Y.; Wu, D.; Zhang, M. Crystallization deformation of a saline soil during freezing and thawing processes. Appl. Therm. Eng. 2017, 120, 463-473. [CrossRef]

21. Zheng, Q.; Xia, T.; Ding, Z.; He, S. The effect of periodic intermittency on the cyclic behavior of marine sedimentary clay. Mar. Georesour. Geotechnol. 2018, 37, 945-959. [CrossRef]

22. Tian, H.; Wei, C.; Wei, H.; Zhou, J. Freezing and thawing characteristics of frozen soils: Bound water content and hysteresis phenomenon. Cold Reg. Sci. Technol. 2014, 103, 74-81. [CrossRef]

23. Ishizaki, T.; Maruyama, M.; Furukawa, Y.; Dash, J. Premelting of ice in porous silica glass. J. Cryst. Growth 1996, 163, 455-460. [CrossRef]

24. Tian, H.; Wei, C.; Tan, L. Effect of freezing-thawing cycles on the microstructure of soils: A two-dimensional NMR relaxation analysis. Cold Reg. Sci. Technol. 2019, 158, 106-116. [CrossRef]

25. Hickox, C.E.; McVey, D.F.; Miller, J.B.; Olson, L.O.; Silva, A.J. Thermal conductivity measurements of pacific illite sediment. Int. J. Thermophys. 1986, 7, 755-764. [CrossRef]

26. Sheahan, T.C.; Ladd, C.C.; Germaine, J.T. Rate-Dependent undrained shear behavior of saturated clay. J. Geotech. Eng. 1996, 122, 99-108. [CrossRef]

27. Papakonstantinou, S.; Anagnostou, G.; Pimentel, E. Evaluation of ground freezing data from the Naples subway. Geotech. Eng. 2013, 166, 280-298. [CrossRef]

28. Zhang, L.; MA, W.; Yang, C. Pore water pressure changes of supercooling and ice nucleation stages during freezing point testing. Géotech. Lett. 2015, 5, 39-42. [CrossRef]

29. Otero, L.; Rodríguez, A.C.; Pérez-Mateos, M.; Sanz, P.D. Effects of magnetic fields on freezing: Application to biological products. Compr. Rev. Food Sci. Food Saf. 2016, 15, 646-667. [CrossRef] 
30. Ashworth, R. Apparatus for laboratory freezing-and-thawing tests on concrete specimens. Mag. Concr. Res. 1967, 19, 45-48. [CrossRef]

31. Watanabe, K.; Osada, Y. Simultaneous measurement of unfrozen water content and hydraulic conductivity of partially frozen soil near $0{ }^{\circ} \mathrm{C}$. Cold Reg. Sci. Technol. 2017, 42, 79-84. [CrossRef]

32. Zhang, Y.; Sun, B.; Wen, A.; Cheng, B. Transverse thermal regime difference of high-speed railway roadbed in seasonally frozen regions. Proc. Inst. Civ. Eng. Ground Improv. 2019, 172, 264-273. [CrossRef] 